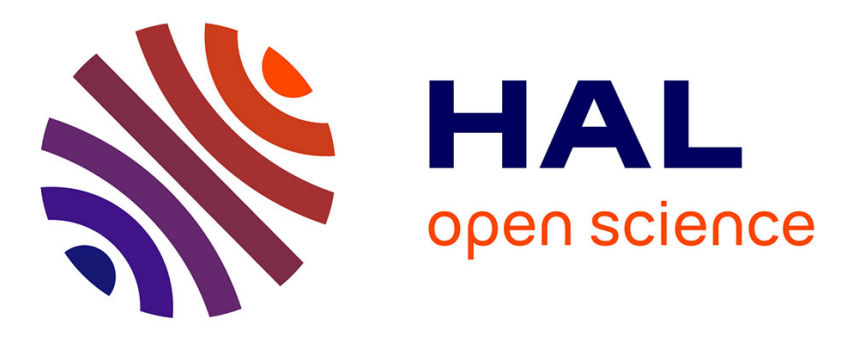

\title{
Cyclodextrin-based systems for the stabilization of metallic(0) nanoparticles and their versatile applications in catalysis
}

Sébastien Noël, Bastien Léger, Anne Ponchel, Karine Philippot, Audrey Denicourt-Nowicki, Alain Roucoux, Eric Monflier

\section{- To cite this version:}

Sébastien Noël, Bastien Léger, Anne Ponchel, Karine Philippot, Audrey Denicourt-Nowicki, et al.. Cyclodextrin-based systems for the stabilization of metallic $(0)$ nanoparticles and their versatile applications in catalysis. Catalysis Today, 2014, 235, pp.20 - 32. 10.1016/j.cattod.2014.03.030 . hal01060956

\section{HAL Id: hal-01060956 https://hal.science/hal-01060956}

Submitted on 4 Sep 2014

HAL is a multi-disciplinary open access archive for the deposit and dissemination of scientific research documents, whether they are published or not. The documents may come from teaching and research institutions in France or abroad, or from public or private research centers.
L'archive ouverte pluridisciplinaire HAL, est destinée au dépôt et à la diffusion de documents scientifiques de niveau recherche, publiés ou non, émanant des établissements d'enseignement et de recherche français ou étrangers, des laboratoires publics ou privés. 


\title{
Cyclodextrin-based systems for the stabilization of metallic(0) nanoparticles and their versatile applications in catalysis
}

Sébastien Noël, ${ }^{\mathrm{a}}$ Bastien Léger, ${ }^{\mathrm{a}}$ Anne Ponchel, ${ }^{\mathrm{a}}$ Karine Philippot, ${ }^{\mathrm{b}, \mathrm{c}}$ Audrey DenicourtNowicki, ${ }^{\mathrm{d} e}$ Alain Roucoux ${ }^{\mathrm{d}, \mathrm{e}}$ and Eric Monflier ${ }^{\mathrm{a} *}$

${ }^{a}$ Université d'Artois, UCCS, UMR CNRS 8181, Faculté des Sciences Jean Perrin, Rue Jean Souvraz SP 18, F-62307 Lens Cedex, France

${ }^{\mathrm{b}}$ CNRS, LCC, 205, Route de Narbonne, F-31077 Toulouse, France

${ }^{\mathrm{c}}$ Université de Toulouse, UPS, INPT, LCC, F-31077 Toulouse, France

${ }^{\mathrm{d}}$ Ecole Normale Supérieure de Chimie de Rennes, CNRS, UMR 6226, 11, Allée de Beaulieu, CS 50837, F-35708 Rennes Cedex 7

${ }^{\text {e}}$ Université européenne de Bretagne

* Corresponding author

Phone: 33 (0)3 21791772

Fax: $33(0) 321791755$

e-mail: eric.monflier@univ-artois.fr

\begin{abstract}
In order to better respond to environmental standards, the development of metal nanoparticles using green approaches has exponentially grown for the last decade. Cyclodextrins, which are cyclic oligosaccharides composed of $6(\alpha), 7(\beta)$ or $8(\gamma)$ glucopyranose units, have appeared to be interesting candidates for the synthesis of metal nanoparticles. Indeed, through the ability to form inclusion complexes or supramolecular adducts with organic molecules or metal precursors, cyclodextrins can be successfully employed to stabilize size-controlled zerovalent metallic nanoparticles active for hydrogenation reactions carried out in aqueous or gas-phase media. In this summary of our works, we report that cyclodextrins could be used in various forms and environments: $i$ ) in free form, $i i)$ in complexed form with appropriate guests molecules, iii) in combination with polymer matrices $i v$ ) in thermosensitive hydrogels and $v$ )
\end{abstract}


immobilized onto porous carbons supports. All these studies highlight the fact that cyclodextrins can be seen as multi-task agents for nanocatalysis.

Keywords: metallic nanoparticles, cyclodextrin, hydrogenation, aqueous phase

\section{Introduction}

Transition-metal nanoparticles (NPs) have attracted a growing interest both in academic and industrial communities in the last decades due to their unique physical properties and their potential applications in biomedical [1], optical [2] and electronic [3] areas as well as in catalysis [4]. Much effort has therefore been focused on the NPs synthesis for catalytic applications by judicious choices (solvent, stabilizing and reducing agents, metal precursors) in order to investigate correlations between synthesis, structure and reactivity. In addition, the efficiency of colloidal metallic particles in catalysis is closely related to the stability issue of the catalytic system in the course of the reaction. The choice of the capping agent is critical as it controls both the size and shape of the particles, but also the dispersion of the metal species, while providing long-term stability during the catalytic process. Moreover, the development of green synthetic approaches, such as aqueous suspensions of nanoparticles, leads researchers to introduce ecofriendly capping agents, such as ammonium salts, water soluble phosphanes, dendrimers, polymers or cyclic oligosaccharides. In this context, cyclodextrins (CDs), which are nontoxic cyclic oligosaccharides consisting of six $(\alpha-C D)$, seven $(\beta-C D)$ or eight ( $\gamma$-CD) $\alpha-1,4$ linked D-glucopyranose units, have appeared to be interesting candidates in the noble metal nanoparticle synthesis (Scheme 1) [5].

\section{< Scheme 1>}

The specific coupling of the glucose monomers gives rise to a rigid conical cylinder whose inner surface is hydrophobic and the outer surface hydrophilic. Through host-guest 
interactions, the internal cavity can form inclusion complex with a large number of organic molecules of appropriate size and shape [5,6]. This complexation property has long been utilized in pharmaceutical, food, cosmetic or textile industries and has found applications in the field of chemical sensing, environmental remediation and catalysis [7-9].

The first example of CD stabilized metal NPs for catalysis was reported by Komiyana in 1983, involving non functionalized CDs, called native CDs [10]. The authors reported that the refluxing of an aqueous solution of rhodium (III) and $\alpha-\mathrm{CD}$ or $\beta-\mathrm{CD}$ in the presence of ethanol gave a colloidal suspension of rhodium particles that could effectively catalyze the hydrogenation of olefins. In another approach, Kaifer and coworkers have extensively described that per-6-thio- $\beta$-CD can effectively stabilized platinum [11], palladium [11-13], silver [14] and gold [15,16] nanoparticles through multiple sulfur bonds between the metal core and the oligosaccharide. Interestingly, it has been found that per-6-thio- $\beta$-CDs-stabilized palladium NPs were effective catalysts for the hydrogenation of $\mathrm{C}=\mathrm{C}$ or $\mathrm{C}=\mathrm{N}$ double bonds [11] and C-C coupling reactions [12]. The efficiency of the nanocatalyst is not only reduced on its stability but also on its capacity to be closed to the substrate in liquid or gas phase in order to convert it.

Our continuous interest in the use of chemically-modified cyclodextrins in catalysis [17-22] has led us to envisage the use of cyclodextrins as stabilizers of aqueous suspensions of noble metal nanoparticles for hydrogenation reactions carried out in aqueous or gas phase conditions. On the basis of our contributions in this field since 2006, we describe that cyclodextrins could be used in various forms and environments: $i$ ) in free form, ii) in complexed form with guest molecules, iii) in combination with polymer matrices, iv) in thermosensitive hydrogels and $v$ ) to immobilize the particles onto porous carbons supports.

More precisely, we showed that i) methylated CDs can be used as metallic NPs capping agents for the hydrogenation of alkenes and arenes in aqueous biphasic conditions. An 
optimization of the NPs synthesis parameters has afforded to get smaller particles size with less cyclodextrin amounts. We will report also that catalytically active metallic nanoparticles can be obtained using ii) inclusion complexes formed between cyclodextrins and ammonium salts or diphosphine ligands or iii) water soluble polymers (in which cyclodextrins are used as co-additives or grafted covalently onto the polymer backbones). Then we will describe that $i v$ ) a supramolecular-based hydrogel with $\alpha$-cyclodextrin has recently proved to be an excellent candidate to lead to stable metallic nanoparticles active in thermoregulated aqueous-phase hydrogenation. Finally, we will extend the applications of cyclodextrins to the preparation of supported heterogeneous catalysts, thus showing that $v$ ) preformed cyclodextrin stabilized metallic NPs can be easily immobilized onto a porous carbon support and successfully used in gas-phase hydrogenation reactions.

\section{Free cyclodextrins as metallic(0) NPs protective agents}

As it has been reported by the group of Kaifer, cyclodextrin-based colloidal suspensions have proven to be stable and active catalysts in hydrogenation or $\mathrm{C}-\mathrm{C}$ coupling reactions $[12,13,23,24]$. In some cases, the cyclodextrins have shown a dual role as NPs stabilizer but also as mass transfer agent. The first studies dealing with the synthesis of $\operatorname{Ru}(0)$ NPs in water using methylated cyclodextrins as protective agents was reported by Monflier and Roucoux $[25,26]$. These cyclodextrins have the advantage to be highly soluble in water, cheap, nontoxic, commercially available and have the property of being surface active [27]. It is worth noting that, generally, these cyclodextrins are not fully methylated and several degrees of substitution (DS) could be obtained (Table 1). These cyclodextrins are named RaMe-CDs.

\section{$<$ Table 1 $>$}




\subsection{Classical preparation}

Catalytic aqueous suspensions of zerovalent Ru nanoparticles are easily prepared by chemical reduction of ruthenium trichloride with an excess of sodium borohydride in dilute aqueous solution of methylated cyclodextrins (Scheme 2).

\section{< Scheme 2>}

In order to get information on the ruthenium nanoparticles stabilized by methylated cyclodextrins, TEM characterization has been performed. As an illustrative example, Fig. 1 shows the TEM picture and corresponding particle size distribution of $\mathrm{Ru}(0)$ nanoparticles synthesized by using RaMe- $\beta-C D$ (1.8) as stabilizer with an optimized ratio of CD to metal of 10 [26]. The ruthenium nanoparticles are organized into non-ordered superstructures with an average particle size of $2.5 \mathrm{~nm}$, with $80 \%$ of the metallic species between 2 and $3 \mathrm{~nm}$.

\section{$<$ Fig. 1 $>$}

The catalytic activity of ruthenium nanoparticles stabilized by 10 equivalents of RaMe- $\beta-C D$ has been evaluated in the hydrogenation of various unsaturated substrates such as long-chain alkenes under 1 bar of hydrogen at room temperature (Table 2).

\section{$<$ Table 2>}

These alkenes were totally hydrogenated in their saturated analogues with TOFs ranging from 12 to $22 \mathrm{~h}^{-1}$. These TOF are modest in comparison to other aqueous nanocatalytic systems but the experimental conditions are less harsch [28]. It is worth noting that the RaMe- $\alpha-\mathrm{CD}$ and 
RaMe- $\gamma$-CD-stabilized NPs were active for the decene hydrogenation (entries 1 and 4). However, the catalytic activity decreased with increasing the chain length $\left(C_{10}>C_{12}>C_{14}\right)$. This phenomenon was already observed in aqueous biphasic organometallic catalysis in the presence of modified cyclodextrins and hydrophobic substrates and this decrease was attributed to a lower solubility of the resulting inclusion complex in water $[29,30]$. The results obtained with RaMe-CD-stabilized $\mathrm{Ru}(0)$ NPs emphasize that the methylated cyclodextrins could play the role of a supramolecular shuttle. The $\mathrm{CD} / \mathrm{Ru}$ molar ratio has been lowered and it appeared that ratios below 10 were not sufficient to obtain stable and catalytically active colloidal suspensions during the reaction course. These observations can be explained by the dual role of the cyclodextrin. Indeed, CDs are not only steric stabilizers but they also act as supramolecular shuttle between the hydrophobic substrate and the nanoparticle surface by forming inclusion complex.

These colloids have been further evaluated in the hydrogenation of various arene derivatives under mild conditions (room temperature, atmospheric hydrogen pressure). The catalytic results have been summarized in Table 3 .

\section{$\langle$ Table 3>}

Very interestingly, the hydrogenation of aromatic rings depends both on the type of methylated cyclodextrin $(\alpha, \beta, \gamma)$ and on the substitution degree (DS). Indeed, when RaMe- $\alpha-$ CD was used as the stabilizer, the aromatic rings were not hydrogenated (entries 5 and 9). In contrast, their total hydrogenation was observed with RaMe- $\gamma$-CD-stabilized $\operatorname{Ru}(0)$ NPs (entries 8 and 12). These results can be explained by the cavity size of the different cyclodextrins which leads to more or less important interactions with the substrates. In the 
case of the RaMe- $\beta-\mathrm{CD}$, the hydrogenation selectivities were related to the substitution degree. For instance, whereas the hydrogenation of styrene is complete with RaMe- $\beta-C D$ (0.7) (entry 6), the hydrogenation of the aromatic ring can be avoided by selecting RaMe- $\beta$ CD (1.8) (entry 7). Notably, this tendency could have been extended to other substrates such as ethylbenzene (entries 10 and 11), allylbenzene (entries 15 and 16) and propylbenzene (entries 17 and 18). These catalytic results can be correlated to the deeper hydrophobic host cavity of the RaMe- $\beta-\mathrm{CD}$ with the highest degree of substitution which can wrap more efficiently the aromatic rings avoiding their hydrogenation [31]. The TOF values are modest compared to others catalytic systems but the reactions were carried out at room temperature under atmospheric hydrogen pressure [28,32].

The obtention of cis-pinanes, important intermediates in perfume and pharmaceutical industries [33,34], by pinene hydrogenation was also explored (Table 4). RaMe-CDsstabilized $\mathrm{Ru}(0) \mathrm{NPs}$ have been tested and compared to ruthenium particles stabilized by $N$, $N$-dimethyl- $N$-cetyl- $N$-(2-hydroxyethyl) ammonium chloride (HEA16Cl), a surfactant which had already proven its efficiency as stabilizer $[35,36]$.

\section{$<$ Table 4>}

As shown in Table 4, all catalytic systems led to the total conversion of the substrate with a cis/trans mixture and no destabilization of the nanoparticles occurred during the reaction course. For both pinenes, the highest diastereoisomeric excess was obtained with RaMe- $\alpha-C D$ (entries 1 and 6) and RaMe- $\gamma$-CD (entries 4 and 9). It is important to note that the stereoselectivities were better with the ruthenium NPs stabilized by methylated cyclodextrins 
than those stabilized by the ammonium surfactant. We could also presume that the cavity of the oligomers and the steric hindrance have a beneficial effect on the diastereoselectivity.

\section{2. other NPs synthesis strategies}

More recently, the synthesis of $\mathrm{Ru}(0)$ NPs from CDs has been performed following two new optimized strategies [37]. The comparison has been made on the size and the dispersion of the resulting particles in the one hand, and also on the stability, the catalytic activity and the selectivity in the hydrogenation of various hydrophobic substrates on the other hand. The two strategies are resumed in Scheme 3.

\section{$<$ Scheme 3>}

The one pot approach has consisted in the hydrogen reduction of ruthenium trichloride salt in presence of RaMe- $\beta$-CD in water. According to preliminary experiments, 5 equivalents were suitable to get stable and active ruthenium NPs [26]. In contrast, the cascade method was carried out in two successive steps. A $\mathrm{Ru}(0)$ hydrosol was obtained by controlled $\mathrm{NaBH}_{4}$ reduction with dropwise addition, with a final $\mathrm{pH}$ value lower than 4.9 in order to avoid particle agglomeration. Then, 5 equivalents of RaMe- $\beta-C D$ were added in the previous hydrosol. Whatever the strategy, stable colloidal suspensions were obtained confirming that randomly methylated cyclodextrins were efficient stabilizers for ruthenium NPs.

The colloidal suspensions have been fully characterized by TEM measurement (Fig. 2).

\section{$<$ Fig. 2>}


As evidenced by TEM measurements, both approaches led to well-dispersed NPs. The one pot strategy allows stabilizing particles with an average diameter of $1.0 \pm 0.2 \mathrm{~nm}$, while the cascade method led to a mean size of $1.4 \pm 0.2 \mathrm{~nm}$. In addition, Dynamic Light Scattering (DLS) experiments [38] were performed on the aqueous suspensions of nanoparticles after one week of preparation and showed the presence of supramolecular edifices around the NPs surface. To have a deeper insight on the interactions between the randomly methylated cyclodextrins and metal surface in both methods, DOSY experiments have been carried out in $\mathrm{D}_{2} \mathrm{O}$ solution $[39,40]$. Whatever the synthesis strategy, similar values of diffusion coefficients and hydrodynamic radius were obtained. Contrary to what is usually observed with strongly interacting ligands, such as phosphines [39,41], the ${ }^{1} \mathrm{H}$ NMR experiments exhibited no significant difference in the chemical shifts of the cyclodextrins indicating weak interactions between the RaMe-CDs and surface of the metallic nanoparticles. Consequently, we could presume the dispersive agent behavior of the cyclodextrin.

The catalytic activity of the ruthenium nanoparticles prepared by each strategy was evaluated in the hydrogenation of several model substrates, including 3-methylanisole, methyl-2acetamidoacrylate and ethylpyruvate under 20 bar of hydrogen. For ethylpyruvate and methyl-2-acetamidoacrylate, the catalytic activities related to the NPs prepared by the cascade method were slightly higher. As an example, the turnover frequencies were $17 \mathrm{~h}^{-1}$ for the cascade strategy against $14 \mathrm{~h}^{-1}$ for the one pot strategy. The possibility of recycling these catalytic systems was investigated on the hydrogenation of ethylpyruvate, and whatever the strategy, it is showed that four successive runs were achieved without any significant loss of stability and activity. 
More interestingly, the performances of the nanocatalysts have been evaluated in the chemoselective hydrogenation of acetophenone (Scheme 4).

< Scheme 4>

\section{$<$ Fig. 3>}

Two reaction intermediates were identified. For both catalysts, $13 \%$ of 1-cyclohexylethanone was measured by gas chromatography, while phenylethanol was detected with a yield up to 30\% (Fig. 3). It was assumed that an inclusion complex between the aromatic ring and the cyclodextrin was formed, thus leading to the preferential hydrogenation of the carbonyl group. To confirm this hypothesis, the hydrogenation of tert-butylacetophenone has been also carried out (Scheme 5). Indeed, tert-butylaromatic compounds are known to be wellrecognized by $\beta$-cyclodextrins, forming 1:1 inclusion complexes with high association constant, typically in the range of $10^{4}-10^{5} \mathrm{M}^{-1}[42,43]$.

\section{$<$ Scheme 5>}

As it was expected, only traces of 1-(4-tert-butylcyclohexyl)ethanone was detected, confirming the mass transfer role of the cyclodextrin. Nevertheless, the catalytic systems were unstable at the end of the reaction, probably due to a too strong interaction between the aromatic substrate and the cyclodextrin cavity.

\subsection{Extension to amino acid grafted-RaMe- $\beta$-CDs}


More recently, these methodologies (one pot and cascade approaches) have been extended to prepare ruthenium NPs stabilized by randomly methylated $\beta$-cyclodextrins grafted with chiral amino-acid moieties, such as L-leucine and L-alanine (Scheme 6) [44].

\section{$<$ Scheme 6>}

The influence of the ligand and synthesis methodology on the size, dispersion and surface properties were studied. These $\mathrm{Ru}(0)$ NPs stabilized by amino acid-grafted RaMe- $\beta$-CD were evaluated in the hydrogenation of prochiral model substrates such as acetophenone, ethyl pyruvate, methyl-2-acetamidoacrylate and 3-methylanisole under 20 bar of $\mathrm{H}_{2}$ at room temperature. The stability of the aqueous colloidal suspensions under reaction conditions was established, indicating that RaMe- $\beta$-CD bearing optically active moieties acts as an efficient protective agent around the nanoparticle surface. In addition, the catalytic data showed that, whatever the strategy, $\mathrm{Ru}(0) \mathrm{NPs}$ containing L-leucine moiety were more active than those capped by RaMe- $\beta$-CD-trz-Ala (respectively $100 \%$ vs $54 \%$ of ethyl-2-hydroxypropanoate). However, no significant enantiomeric excess was measured probably due to the weak or deficient interaction between the chirally modified cyclodextrin and the nanoparticle surface.

\section{NPs stabilization by a host-guest complex}

As an extension to our previous studies, the influence of methylated cyclodextrins on the synthesis and catalytic activity of metallic NPs protected by stabilizing agents, e.g. ammonium salts $[35,36]$ or diphosphine compounds [39], was also investigated. 


\subsection{Stabilization by cyclodextrin-alkyl ammonium salt combination}

Ionic surfactants such as alkyl ammonium salts are known to be good candidates to stabilize active metallic NPs [35,36]. Moreover, this family of surfactants is well-known to strongly interact with $\beta-C D$ derivatives [45]. The synthesis of aqueous zerovalent ruthenium NPs stabilized by an inclusion complex composed of randomly methylated cyclodextrins with ammonium salts bearing a lipophilic chain was investigated [46]. NMR spectroscopic studies were performed to prove the formation in water of an inclusion complex between RaMe- $\beta$ $\mathrm{CD}$ and the chloride salt of N,N-dimethyl,N-hexadecyl,N-(2-hydroxyethyl)ammonium (HEA16Cl). The continuous variation technique, named Job's method, emphasized the existence of such a complex (Fig. 4).

\section{$<$ Fig. 4>}

The ${ }^{1} \mathrm{H}$ NMR spectra of aqueous solutions containing different ratios of CD to surfactant exhibited chemical shifts variations for both the protons of $\mathrm{HEA} 16 \mathrm{Cl}$ and cyclodextrin, in agreement with a 1:1 stoechiometry of the inclusion complex. Additional T-ROESY experiments also confirmed the existence of an inclusion complex (Fig. 5).

\section{$<$ Fig. 5>}

The $\mathrm{Ru}(0) \mathrm{NPs}$ stabilized by the mixture HEA16Cl/RaMe- $\beta-\mathrm{CD}$ were synthesized following a specific procedure [46]. Briefly, sodium borohydride was added to an aqueous solution containing the surfactant and RaMe- $\beta-\mathrm{CD}$ and was quickly added to a ruthenium chloride solution (HEA16Cl:CD:Ru = 1:1:1). The reduction instantaneously occurred and a color change was observed. The resulting nanoparticles were characterized by transmission 
electronic microscopy and showed a homogeneous distribution with an average size of about $4 \mathrm{~nm}$. The particles were organized in super-structures similarly to those previously observed with the $\mathrm{Ru}(0) \mathrm{NPs}$ stabilized by the uncomplexed RaMe- $\beta-\mathrm{CD}$ [26]. The catalytic activity of the $\mathrm{Ru}(0)$ colloidal suspension stabilized by $\mathrm{RaMe}-\beta-\mathrm{CD}: \mathrm{HEA} 16 \mathrm{Cl}$ mixture in a ratio $1: 1$ was evaluated in the hydrogenation of several functionalized aromatic compounds (i.e. anisole, toluene and styrene) and their performances were compared to the $\mathrm{Ru}(0)$ nanoparticles prepared using only the ammonium salt surfactant (Table 5).

\section{$<$ Table 5>}

Whatever the substrate, the RaMe- $\beta-\mathrm{CD} / \mathrm{HEA} 16 \mathrm{Cl}$ stabilized Ru(0) NPs was the most active catalytic system, indicating a beneficial effect of the inclusion complex as stabilizer. In the case of anisole, the catalytic activity of the above NPs is three times higher than the NPs stabilized by the ammonium surfactant. The same tendency is observed for the toluene and styrene hydrogenation. The difference of activity was related to a different organization of the stabilizer around the metal surface. Indeed, whereas the $\mathrm{Ru}(0) \mathrm{NPs}$ stabilized by $\mathrm{HEA} 16 \mathrm{Cl}$ were protected by a surfactant double layer, as already described by other groups $[47,48]$, it was suggested that RaMe- $\beta-\mathrm{CD}$ affected the adsorption of the surfactant on the metal surface and prevented the double layer formation. The cyclodextrin could act as a spacer between the alkyl chains and reduced the intermolecular interactions, thus allowing a better mobility and diffusion of the substrate at the vicinity of the metal surface. Moreover, a partial release of the cyclodextrin (controlled by the thermodynamic equilibrium of the host-guest complex) is also possible and this would reduce the steric hindrance around the particle and lead some free cyclodextrins to be more available to solubilize the organic substrate in water (Scheme 7). 


\section{< Scheme 7>}

\subsection{Stabilization by cyclodextrin-hydrosoluble diphosphine combination}

Cyclodextrins have long been used as mass-transfer promoters in biphasic aqueous phase catalysis processes using water soluble organometallic complexes with sulfonated phosphines as ligands $[17,49,50]$. Spectroscopic studies demonstrated that, depending on nature and position of the substituents on the aromatic ring, sulfonated phosphines can interact with RaMe- $\beta-C D$ by forming inclusion complexes and tune the catalytic performances of the metal centers $[43,51]$. On the basis of previous results in the organometallic synthesis of waterdispersed zerovalent ruthenium NPs by employing alkyl sulfonated diphosphines (which showed interesting catalytic activities for the hydrogenation of unsaturated substrates in aqueous biphasic conditions) [52], the effect of the addition of cyclodextrin to sulfonated diphosphines was also investigated. The idea was to combine the advantages of a sulfonated diphosphine as water soluble stabilizer of NPs with a cyclodextrin for its shuttle and supramolecular control effects in biphasic aqueous phase catalysis [53]. The objective was to get stable water-soluble ruthenium NPs, to characterize their surface state (in particular, identification of diphosphine/RaMe- $\beta-\mathrm{CD}$ association close to the metal surface if present) and to study their catalytic behavior in terms of activity and selectivity during the hydrogenation of aromatic substrates. Thus, ruthenium nanoparticles were synthesized by hydrogen reduction of the organometallic ruthenium complex $[\mathrm{Ru}(\operatorname{cod})(\cot )]$ and stabilized either with 1,4-bis[(di-m-sulfonatophenyl)phosphine]butane (dppbs) or its combination with RaMe- $\beta-C D$ in THF. The so-obtained $\mathrm{Ru}(0)$ NPs were isolated by precipitation and finally easily re-dispersed in water [52].

\section{$<$ Scheme 8>}


The ability of the resulting NPs to be easily re-dispersed in water was related to a strong $\sigma$ coordination of the phosphorous atom to the metal surface and coulombic repulsion of the charged sulfonated groups of the ligand molecules [39,54]. The synthesized nanoparticles (diphosphine alone and phosphine-cyclodextrin mixture) were fully characterized by several techniques (TEM, HRTEM, WAXS, DLS, liquid and solid NMR spectroscopy). Whatever the stabilizer (without or with CD as co-additive), TEM images showed small and well-dispersed particles with an average diameter between 1.2 and $1.5 \mathrm{~nm}$. It is interesting to note that the precipitation-redispersion of the $\mathrm{Ru}(0)$ NPs changed neither the dispersion nor the average size. The NPs environment in solution was studied by DLS. The results showed that the hydrodynamic radius depended on the amount of cyclodextrin present during the NPs synthesis which is a strong indication that the cyclodextrins surround the metal particles surface.

Deep-NMR experiments in water allowed evidencing the interaction between the aromatic rings of the diphosphine and the cavity of the cyclodextrin. Resonance shifts in ${ }^{1} \mathrm{H}$ and ${ }^{31} \mathrm{P}$ NMR in $\mathrm{D}_{2} \mathrm{O}$ confirmed the presence of a weak interaction between the dppbs and RaMe- $\beta$ $\mathrm{CD}$ (aromatic protons and protons which are in the cyclodextrin cavity) and a fast exchange between associated and dissociated states by variations of the diffusion coefficient of CD and diphosphine. The formation of an inclusion complex was also confirmed by the presence of a split in 2 resonances for the diphosphine $\left({ }^{31} \mathrm{P}\right.$ and ${ }^{13} \mathrm{C}$ CPMAS NMR). NMR experiments showed also that the diphosphine/CD mixture induced a strong reduction in the affinity of the sulfonated ligand towards the metal surface, indicating that CDs were located close to it. However, the addition of RaMe- $\beta-\mathrm{CD}$ on a preformed dppbs-stabilized $\mathrm{Ru}(0)$ NPs solution did not change the NMR spectra, thus evidencing that the dppbs/CD complex was formed only if the diphosphine and cyclodextrin were both present in the beginning of the synthesis. 
In order to investigate the influence of the cyclodextrin on the catalytic performances of the diphosphine-stabilized NPs, the hydrogenation of model compounds such as styrene, acetophenone and $m$-methylanisole was carried out (Table 6).

\section{$<$ Table 6>}

Based on TOF values, whatever the substrate, an activity improvement was observed with increasing the initial amount of cyclodextrin. More interestingly, in the case of $\mathrm{m}$ methylanisole, we observed that the quantity of cyclodextrin dramatically influenced the stereoselectivity towards the preferential formation of the cis isomer (51\% vs $100 \%$ for dppbs and dppbs/5.0 CD respectively).

\section{NPs and polymers}

Contrary to the previous nanoparticle systems stabilized with molecular cyclodextrins or hostguest associations, the possibility of using water soluble polymer backbones in the presence of cyclodextrins has been explored for the synthesis of metallic colloidal suspensions. Two main strategies were investigated: $i$ ) physical mixture of polymers and cyclodextrins and $i i$ ) cyclodextrin-grafted polymers.

\subsection{Physical mixtures}

Among the water-soluble capping agents, polymers are widely used to stabilize metal NPs [55-59]. The use of cyclodextrins as additives in the synthesis of poly $(N$-vinyl-2pyrrolidone)-stabilized metal NPs in colloidal suspensions, was studied [60]. The idea was to take advantage of the amphiphilic properties of CDs as well as their ability in stabilizing molecule-metal ion adducts with inorganic salts to control the size of the particles. For this 
purpose, ruthenium NPs were synthesized in the presence of poly( $N$-vinyl-2-pyrrolidone)/CD mixture of controlled ratio and the TEM images of the corresponding particles were carefully compared. For the standard $\mathrm{Ru}(0) \mathrm{NPs}$, i.e. $\mathrm{Ru}(0)$ NPs stabilized by poly $(N$-vinyl-2pyrrolidone) (PVP) alone, the particles were entrapped in string-like assemblies by the effect of PVP chains [61]. The morphology did not seem to be altered by the presence of cyclodextrin. However, a slight decrease in the mean particle size was noticed when cyclodextrins were added to the PVP $(2.5$ and $2.3 \mathrm{~nm}$ with $\beta-\mathrm{CD}$ and RaMe- $\beta-\mathrm{CD}$, respectively against $3.0 \mathrm{~nm}$ without cyclodextrin). ${ }^{1} \mathrm{H}$ and T-ROESY NMR experiments did not reveal any evidence of the inclusion of some parts of the PVP within the hydrophobic cavity. DOSY analyses showed that the diffusion coefficient was similar to that of the pure polymer. On the other hand, the well-known aggregation of cyclodextrins in aqueous solutions, which can give rise to large agglomerates in the 200-300 $\mathrm{nm}$ range [62], was deeply disturbed by the presence of PVP. According to the DLS experiments, we observed that these CD aggregates had the tendency to significantly disappear in the presence of PVP in the favor of small-sized assemblies of only 2 or 3 cyclodextrin units as evidenced by the presence of a band at about 2-3 $\mathrm{nm}$. The disaggregated CDs were assumed to interact easier with the soluble $\mathrm{Ru}$ (III) precursor than PVP, thus increasing the efficiency in controlling the growth of the $\mathrm{Ru}(0)$ after the reduction step (Scheme 9).

\section{$<$ Scheme 9>}

To confirm this hypothesis, an additional experiment was realized, in which the CDs were added to a preformed PVP-stabilized Ru colloidal suspension and kept stirred during 24 supplementary hours. Notably, the size range of the particles was the same to that of the control preparation (without CDs). It is important to mention that the presence of PVP was 
crucial in order to ensure long term stability of the $\mathrm{Ru}(0) \mathrm{NPs}$, knowing that a ratio of PVP to Ru higher than 8 was absolutely required.

The influence of the quantity of cyclodextrin on the catalytic activity of the resulting $R u(0)$ NPs was studied, performing for the hydrogenation of furfural [63-65], a bio-sourced substrate, in mild conditions $\left(30^{\circ} \mathrm{C}, 10\right.$ bar of $\left.\mathrm{H}_{2}\right)$.

\section{$<$ Table 7>}

Whatever the PVP/CD ratio, the ruthenium NPs were visually stable and no sedimentation was observed at the end of the catalytic test. According to the results gathered in Table 7, only a small amount of cyclodextrin was required to get an activity improvement. The obtained results were rationalized in terms of size and morphology control of the $\mathrm{Ru}(0) \mathrm{NPs}$. In line with what is generally observed in nanocatalysis, the decrease in the particle size results in the increase of the number of available surface active sites, and consequently, increases the catalytic efficiency.

\subsection{Cyclodextrin-based polymer}

Recently, the possibility of stabilizing metallic NPs by using a 2D-polymeric structure combining different types of stabilizing groups (i.e. carboxylate groups, polymeric structure and cyclodextrin) was also investigated (Scheme 10) [66].

\section{$<$ Scheme 10>}


The advantage of this strategy was to provide steric and electrostatic interactions within a single polymer matrix in order to stabilize robust nanoparticles. Interestingly, this approach was proposed to favor the interactions between the substrate and active sites at the surface of the metal NPs and was successfully applied to the case of rhodium. For this purpose, rhodium trichloride was reduced by sodium borohydride in the presence of poly(mono( $\beta$-cyclodextrin2-yl)-maleate-alt-maleate-alt-methylvinylether). Note that a control experiment was performed using the same polymer backbone but without any presence of grafted cyclodextrin. The two colloidal suspensions were characterized by TEM and the corresponding images clearly showed two different types of nanoparticles organization (Fig. $6)$.

\section{$<$ Fig. 6>}

Thus for the $\mathrm{Rh}(0)$ particles stabilized by the polymer containing cyclodextrins, a mono and well-dispersed size distribution was clearly obtained. The average particle size was about 2.5 $\mathrm{nm}$ with $80 \%$ of the NPs between 2 and $3 \mathrm{~nm}$. In contrast, the rhodium nanoparticles prepared from the cyclodextrin-free polycarboxylate (control polymer) was organized in non-ordered superstructures, in which the NPs were entrapped in string-like assemblies, as previously observed for PVP-stabilized ruthenium NPs. In addition, a broader particle size distribution (2 $-6.5 \mathrm{~nm})$ and a larger mean particle size $(3.8 \mathrm{~nm})$ were obtained.

The catalytic properties were evaluated in the hydrogenation of various alkene and arene derivatives. For instance, in the case of 1-tetradecene, the TOF were equal to $2000 \mathrm{~h}^{-1}$ and 420 $\mathrm{h}^{-1}$ for the hydrogenation reaction catalyzed by $\mathrm{Rh}(0)$ NPs stabilized by polyCOONa- $-\beta-\mathrm{CD}$ and polyCOONa, respectively. These results were correlated with both the average particle size and the dispersion of the rhodium particles stabilized by the above stabilizers. In order to 
a have a better insight on the beneficial effect of the structure of the polymer, an additional experiment has been performed using a physical mixture, i.e. adding the same amount of $\beta$ $\mathrm{CD}$ in the polycarboxylate solution. The TOF was equal to $400 \mathrm{~h}^{-1}$, very close to the value of the polycarboxylate alone but the colloidal suspension after the catalytic test was unstable. All these experiments undoubtedly supported the view that the $\beta-\mathrm{CD}$ covalently linked to the polymer chain induced a significant effect in terms of activity and reusability. The involvement of a recognition process between the cyclodextrin cavity and the hydrophobic substrate could be confirmed by the 1-tetradecene hydrogenation in presence of 1adamantane-carboxylate sodium salt, which is known to strongly interact with $\beta$-CD [31]. Thus, an activity decrease was measured when the guest was added and this result confirmed that the cyclodextrin influenced the catalytic behavior of the NPs by facilitating the meeting of the substrate with the metal surface.

The recyclability was studied by reusing the aqueous catalytic layer in five successive hydrogenation runs of 1-tetradecene. No loss of stability and activity was noted. The rhodium leaching in the organic phase of each catalytic test was very low $(<0.2 \mathrm{ppm})$ while the TEM experiments confirmed the robustness of the colloidal suspensions, with no change in terms of particle size and morphology.

\section{Cyclodextrin-based Hydrogels}

Hydrogels are hydrophilic polymer networks that can absorb a large amount of water but not be dissolved in water. For this reason, hydrogels have become popular in several applications including catalysis [67]. For instance, polymer hydrogels proved to be efficient templates for the in-situ synthesis of metal NPs. Even if these metal particles are embedded in the polymer matrix, they showed catalytic activity. In parallel, responsive hydrogels can also undergo a swelling transition in response to environmental stimuli such as temperature, light or $\mathrm{pH}$. 
Indeed, the thermoreversibility allows the NPs stabilization at room temperature and their activation at high temperature. More precisely, once that metal NPs have been embedded into the supramolecular matrix, the system can be heated above the sol-gel transition temperature to give a sol phase where the catalytic reaction can take place.

In our case, the polypseudorotaxane [68] template could have been prepared from a mixture of $\mathrm{N}$-alkylpyridinium amphiphilic [py- $\left.\mathrm{N}-\left(\mathrm{CH}_{2}\right)_{12} \mathrm{OC}_{6} \mathrm{H}_{3}-3,5-(\mathrm{OMe})_{2}\right]^{+}\left(\mathrm{Br}^{-}\right)$and $\alpha-\mathrm{CD}$ in the ratio of 1:2 (Scheme 11). The self-assembly of these molecules yields a thermoresponsive hydrogel, with a sol-gel transition temperature of $42^{\circ} \mathrm{C}$.

\section{< Scheme 11>}

The synthesis of Ru NPs was realized by classical chemical reduction of the chloride salt of ruthenium solubilized in the hydrogel at the sol state $\left(50^{\circ} \mathrm{C}\right)$ by an excess of sodium borohydride. TEM analysis clearly highlighted the stabilization of a homogeneous dispersion of spherical $\mathrm{Ru}(0) \mathrm{NPs}$ with an average diameter of $1.6 \mathrm{~nm}$ within the hydrogel network, which is smaller than that observed using surfactants $[26,46]$ or ionic liquids [69] as $\mathrm{Ru}(0)$ NPs stabilizers. This result emphasized the effective control exerted by the hydrogel internal network structure over the Ru NPs growth.

\section{$<$ Fig. 7 >}

Very interestingly, the concept has been validated for the catalytic hydrogenation of various substrates, ranging from hydrophobic long-chain to hydrophilic olefins, such as 2-methyl-3buten-2-ol. Under $\mathrm{H}_{2}$ pressure ranging from 10 to 40 bar at $50^{\circ} \mathrm{C}$, TOF values comprised between 4 to $350 \mathrm{~h}^{-1}$ were obtained. At the end of the catalytic test, after cooling to ambient temperature, the hydrogel spontaneously returned to the gel state and consequently the 
products could be easily recovered. The recycling of the NPs entrapped in the hydrogel has been successfully performed using 1-decene.

\section{< Scheme 12>}

\section{Adsorption of CD-stabilized metal (0) NPs onto porous materials}

The development of efficient heterogeneous catalytic systems is a well-developed research area both in academic and industrial domains. Among the methods which are referenced to obtain supported metallic nanoparticles, their deposition onto a porous support from stabilized colloidal suspensions has received considerable attention over the past decade. At the end of the synthesis, the excess stabilizing molecules can be removed from the nanoparticle surface by washing or thermal treatments to increase the accessibility of active sites to reactants and intermediates. However, the design of well-structured and stable supported metal NPs should take into account not only the stability of the solvent dispersed particles, but also the metalsupport interactions that exert a dominant effect during the deposition step. Thus among the materials used as carriers for nanoparticles immobilization, porous carbon materials are of increasing interest because of their attractive physicochemical properties (e.g. high pore volume, large surface area, high thermal and chemical stabilities, high adsorption capacity). In this context and knowing that cyclodextrins can act as efficient protective agents for the stabilization of ruthenium NPs in aqueous phase and can spontaneously adsorb onto carbon supports [70], we have studied their use in the preparation of carbon-supported ruthenium catalysts for gas-phase hydrogenation reactions. The idea was to take advantage of an easy anchoring of the metallic nanoparticles onto the carbon support via the cyclodextrin combined with interesting activities and selectivities. 
To validate the strategy, a series of carbon-supported ruthenium nanocatalysts were prepared by the adsorption on a porous activated carbon of $\mathrm{Ru}(0) \mathrm{NPs}$ pre-formed in aqueous solution by chemical reduction of $\mathrm{RuCl}_{3}$ in the presence of RaMe-CD ( $\alpha-, \beta$ - and $\gamma$-) [71,72]. After the adsorption step, the solids were recovered by filtration and thoroughly washed with water. According to nitrogen adsorption measurements, it has clearly been shown that the immobilization of the RaMe-CD-stabilized $\mathrm{Ru}(0)$ NPs by deeply affected the textural properties of the porous carbon carrier. It was interesting to note that, whatever the initial molar ratio of $\mathrm{CD}$ to $\mathrm{RuCl}_{3}$, the $\mathrm{Ru}$ content was about $1.4 \pm 0.2$ wt. \%. In addition, thermogravimetric measurements proved that the prepared nanocatalysts were thermally stable up to $235^{\circ} \mathrm{C}$ under both inert and reducing atmospheres. Finally, the study of the dispersion and morphology of the supported particles were carried out by TEM analysis. For instance, the TEM characterization of the $\mathrm{Ru}-3 \beta-\mathrm{CD} / \mathrm{C}$ sample for which the $\mathrm{Ru}(0)$ nanoparticles were synthesized with a 3:1 ratio of $\mathrm{RaMe}-\beta-\mathrm{CD}$ to $\mathrm{Ru}$ showed that nanoparticles had a spherical shape with an average diameter of $2.4 \mathrm{~nm}$ (Fig. 8).

\section{$<$ Fig. 8 $>$}

The catalytic activity of the carbon supported RaMe-CD stabilized Ru NPs was evaluated in the hydrogenation of xylene isomers in gas phase at $85^{\circ} \mathrm{C}$.

\section{$<$ Table 8>}

First, the catalytic results have clearly shown that the $R u(0)$ nanocatalysts prepared with randomly methylated cyclodextrins are more efficient than the control $\mathrm{Ru} / \mathrm{C}$ (entries 1 and 8). However, the catalytic activity depends on the cyclodextrin size and initial CD/Ru ratio. The 
best results have been obtained with RaMe- $\beta-\mathrm{CD}$ with a molar ratio of cyclodextrin to ruthenium of 3 . When this ratio is greater, a lower accessibility of the substrate to the metal site is postulated, leading to an activity decrease. In terms of stereoselectivity, the trans to cis ratio is improved in the presence of CDs-based catalysts, and thus whatever the substrate. These results can be explained by several factors such as the dispersion of the active species through a promoter effect of the CD and the host-guest interactions occurring between the substrate and cyclodextrin, which is adsorbed onto the particles. The hydrogenation of a mixture of xylene isomers (ortho- and para-) has also been studied (Fig. 9).

\section{$<$ Fig. 9>}

It has been shown that carrying out the hydrogenation of a mixture of $o$ - and $p$-xylene (420 and $580 \mathrm{ppm}$, respectively) instead of pure xylene led to major changes in the catalytic reaction. Thus, an inhibition effect of the xylene hydrogenation is observed especially for the $\mathrm{Ru} / \mathrm{C}, \mathrm{Ru}-3-\alpha \mathrm{CD} / \mathrm{C}$ and $\mathrm{Ru}-3-\gamma \mathrm{CD} / \mathrm{C}$ samples as evidenced by the cumulated TOF values. It seems that a competitive adsorption of the aromatic substrates occurs on the same active sites of the catalyst and that in particular $o$-xylene plays the role of a pseudo-poison for the hydrogenation of $p$-xylene. Interestingly, the aforementioned inhibition effect is significantly reduced by using RaMe- $\beta-\mathrm{CD}$, showing again that the $\mathrm{Ru}-3-\beta C D / C$ sample remains the most effective catalyst for the hydrogenation of xylenes (tested separately or in mixture).

\section{Conclusions and perspectives}

In this review, we have demonstrated that cyclodextrins, especially randomly methylated, could be seen as a multitask agent for the preparation of nanoheterogeneous catalysts. From the first stages of the NPs synthesis to the catalytic process, these water-soluble cyclic and 
nontoxic oligosaccharides have proven their utility and efficiency to get stable, active and recyclable catalysts, dispersed in solution or supported onto carbon support. All colloidal systems keep stable (no metal sedimentation) at the end of the catalytic test. Except the case of metal NPs embedded in a hydrogel structure, a large range of substrates, petro and biosourced, has been converted under mild experimental conditions (room temperature- $30^{\circ} \mathrm{C}$ and 1-20 bar of hydrogen) in short times (less than 6 hours). We have highlighted that RaMe-CDs could not only be seen as a stabilizing agent, but also as dispersing agent and could further serve as mass transfer agents in aqueous biphasic catalytic reactions. When NPs are stabilized by surfactants, diphosphines or polymers in presence of free cyclodextrins, a beneficial effect in the synthesis has been obtained by decreasing particles size, improving distribution and robustness. These improvements could be assigned to potential inclusion complexes or rupture of natural cyclodextrin aggregates. Another way to get highly stable and active metal NPs is the use of a combination of stabilizers (polymers and cyclodextrins) by the synthesis of cyclodextrin-based polymers where cyclodextrins are covalently linked to the polymer backbone. The polyCOO- $g-\beta-\mathrm{CD}(\mathrm{x}=0.04)$-stabilized $\mathrm{Rh}(0)$ NPs have shown higher activities than the particles without cyclodextrin (polyCOONa) or the particles stabilized by the physical mixture (polyCOONa $+\beta-\mathrm{CD}$ ). This review also showed that cyclodextrins have good affinity with carbonaceous supports via the adsorption of the NPs. Recent studies have shown that cyclodextrins could serve as active phase dispersant on inorganic support by the formation of supramolecular adducts between the cyclodextrin and the metal salt [73,74]. For instance, $\mathrm{ZrO}_{2}$ supported cobalt oxide NPs have been synthesized and have shown activity in the formaldehyde oxidation. In the future, this strategy could be applied for the synthesis of supported zerovalent metal nanoparticles. Finally, all these different aspects clearly showed that cyclodextrins are multitask agents in nanocatalysis. 


\section{Acknowledgements}

The authors are grateful to CNRS, to the Agence Nationale de la Recherche (ANR-09-BLAN0194) for the financial support of the SUPRANANO program and to Roquette Frères (Lestrem, France) for the generous gift of cyclodextrins. 


\section{References}

[1] N.T.K. Thanh, L.A.W. Green, Nano Today 5 (2010) 213-230.

[2] K.L. Kelly, E. Coronado, L.L. Zhao, G.C. Schatz, J. Phys. Chem. B 107 (2003) 668677.

[3] S.M. Choi, M.H. Seo, H.J. Kim, W.B. Kim, Synth. Met. 161 (2011) 2405-2411.

[4] A. Roucoux, J. Schulz, H. Patin, Chem. Rev. 102 (2002) 3757-3778.

[5] J. Szejtli, Chem. Rev. 98 (1998) 1743-1754.

[6] H.-J. Schneider, F. Hacket, V. Rüdiger, H. Ikeda, Chem. Rev. 98 (1998) 1755-1786.

[7] F. Hapiot, S. Tilloy, E. Monflier, Chem. Rev. 106 (2006) 767-781.

[8] L.X. Song, M. Wang, Z. Dang, F.Y. Du, J. Phys. Chem. B 114 (2010) 3404-3410.

[9] A. Denicourt-Nowicki, A. Roucoux, Curr. Org. Chem. 14 (2010) 1266-1283.

[10] M. Komiyama, H. Hirai, Bull. Chem. Soc. Jpn. 56 (1983) 2833-2834.

[11] J. Alvarez, J. Liu, E. Román, A.E. Kaifer, Chem. Commun. 36 (2000) 1151-1152.

[12] L. Strimbu, J. Liu, A.E. Kaifer, Langmuir 19 (2003) 483-485.

[13] J. Liu, J. Alvarez, W. Ong, E. Román, A.E. Kaifer, Langmuir 17 (2001) 6762-6764.

[14] J. Liu, W. Ong, A.E. Kaifer, C. Peinador, Langmuir 18 (2002) 5981-5983.

[15] L.A. Godínez, J. Lin, M. Muñoz, A.W. Coleman, S. Rubin, A. Parikh, T.A. Zawodzinski, D. Loveday, J.P. Ferraris, A.E. Kaifer, Langmuir 14 (1998) 137-144.

[16] J. Liu, W. Ong, E. Román, M.J. Lynn, A.E. Kaifer, Langmuir 16 (2000) 3000-3002.

[17] F. Hapiot, A. Ponchel, S. Tilloy, E. Monflier, C. R. Chim. 14 (2011) 149-166.

[18] S. Tilloy, H. Bricout, E. Monflier, Green Chem. 4 (2002) 188-193.

[19] H. Bricout, F. Hapiot, A. Ponchel, S. Tilloy, E. Monflier, Curr. Org. Chem. 14 (2010) 1296-1307.

[20] C. Blaszkiewicz, H. Bricout, E. Léonard, C. Len, D. Landy, C. Cézard, F. DjedaïniPilard, E. Monflier, S. Tilloy, Chem. Commun. 49 (2013) 6989-9691.

[21] J. Potier, S. Menuel, D. Fournier, S. Fourmentin, P. Woisel, E. Monflier, F. Hapiot, ACS Catal. 2 (2012) 1417-1420. 
[22] D. Kirschner, T. Green, F. Hapiot, S. Tilloy, L. Leclercq, H. Bricout, E. Monflier, Adv. Synth. Catal. 348 (2006) 379-386.

[23] C. Xue, K. Palaniappan, G. Arumugam, S.A. Hackney, J. Liu, H. Liu, Catal. Lett. 116 (2007) 94-100.

[24] S.C. Mhadgut, K. Palaniappan, M. Thimmaiah, S.A. Hackney, B. Török, J. Liu, Chem. Commun. 41 (2005) 3207-3209.

[25] A. Nowicki, Y. Zhang, B. Leger, J.P. Rolland, H. Bricout, E. Monflier, A. Roucoux, Chem. Commun. 42 (2006) 296-298.

[26] A. Denicourt-Nowicki, A. Ponchel, E. Monflier, A. Roucoux, Dalton Trans. 36 (2007) 5714-5719.

[27] L. Leclercq, H. Bricout, S. Tilloy, E. Monflier, J. Colloid Interface Sci. 307 (2007) 481-487.

[28] F. Lu, J. Liu, J. Xu, Adv. Synth. Catal. 348 (2006) 857-861.

[29] E. Monflier, S. Tilloy, G. Fremy, Y. Barbaux, A. Mortreux, Tetrahedron Lett. 36 (1995) 387-388.

[30] E. Monflier, S. Tilloy, G. Fremy, Y. Castanet, A. Mortreux, Tetrahedron Lett. 36 (1995) 9481-9484.

[31] M. V. Rekharsky, Y. Inoue, Chem. Rev. 98 (1998) 1875-1918.

[32] A. Nowicki, V. Le Boulaire, A. Roucoux, Adv. Synth. Catal. 349 (2007) 2326-2330.

[33] D. Chouchi, D. Gourgouillon, M. Courel, J. Vital, M. Nunes da Ponte, Ind. Eng. Chem. Res. 40 (2001) 2551-2554.

[34] S.H. Ko, T.C. Chou, Ind. Eng. Chem. Res. 32 (1993) 1579-1587.

[35] A. Roucoux, J. Schulz, H. Patin, Adv. Synth. Catal. 345 (2003) 222-229.

[36] J. Schulz, S. Levigne, A. Roucoux, H. Patin, Adv. Synth. Catal. 344 (2002) 266-269.

[37] N.T.T. Chau, S. Handjani, J.P. Guegan, M. Guerrero, E. Monflier, K. Philippot, A. Roucoux, ChemCatChem 5 (2013) 1497-1503.

[38] B. Chu, T. Liu, J. Nanoparticle Res. 2 (2000) 29-41.

[39] P.J. Debouttière, Y. Coppel, A. Denicourt-Nowicki, A. Roucoux, B. Chaudret, K. Philippot, Eur. J. Inorg. Chem. 2012 (2012) 1229-1236.

[40] Y. Cohen, L. Avram, L. Frish, Angew. Chem. Int. Ed. 44 (2005) 520-554.

[41] P. Lara, K. Philippot, B. Chaudret, ChemCatChem 5 (2013) 28-45. 
[42] T. Hoefler, G. Wenz, J. Incl. Phenom. Mol. Recognit. Chem. 25 (1996) 81-84.

[43] L. Caron, H. Bricout, S. Tilloy, A. Ponchel, D. Landy, S. Fourmentin, E. Monflier, Adv. Synth. Catal. 346 (2004) 1449-1456.

[44] N.T.T. Chau, J.P. Guégan, S. Menuel, M. Guerrero, F. Hapiot, E. Monflier, K. Philippot, A. Denicourt-Nowicki, A. Roucoux, Appl. Catal. A Gen. 467 (2013) 497503.

[45] B. Tutaj, A. Kasprzyk, J. Czapkiewicz, J. Incl. Phenom. 47 (2003) 133-136.

[46] C. Hubert, A. Denicourt-Nowicki, A. Roucoux, D. Landy, B. Leger, G. Crowyn, E. Monflier, Chem. Commun. 45 (2009) 1228-1230.

[47] S.-H. Wu, D.H. Chen, J. Colloid Interface Sci. 273 (2004) 165-169.

[48] B. Nikoobakht, M.A. El-Sayed, Langmuir 17 (2001) 6368-6374.

[49] P. Blach, D. Landy, S. Fourmentin, G. Surpateanu, H. Bricout, A. Ponchel, F. Hapiot, E. Monflier, Adv. Synth. Catal. 347 (2005) 1301-1307.

[50] S. Tilloy, G. Crowyn, E. Monflier, P.W.N.M. van Leeuwen, J.N.H. Reek, New J. Chem. 30 (2006) 377.

[51] M. Ferreira, H. Bricout, A. Sayede, A. Ponchel, S. Fourmentin, S. Tilloy, E. Monflier, Adv. Synth. Catal. 350 (2008) 609-618.

[52] M. Guerrero, A. Roucoux, A. Denicourt-Nowicki, H. Bricout, E. Monflier, V. Collière, K. Philippot, Catal. Today 183 (2012) 34-41.

[53] M. Guerrero, Y. Coppel, N.T.T. Chau, A. Roucoux, A. Denicourt-Nowicki, E. Monflier, K. Philippot, ChemCatChem 5 (2013) 3802-3811.

[54] P.J. Debouttière, V. Martinez, K. Philippot, B. Chaudret, Dalton Trans. 38 (2009) $10172-4$.

[55] C. Pan, K. Pelzer, K. Philippot, B. Chaudret, F. Dassenoy, P. Lecante, M.J. Casanove, J. Am. Chem. Soc. 123 (2001) 7584-7593.

[56] G.J. Vancso, P. Alexandridis, M. Tsianou, Eur. Polym. J. 47 (2011) 569-583.

[57] Y. Li, E. Boone, M.A. El-Sayed, Langmuir 18 (2002) 4921-4925.

[58] N. Gacem, P. Diao, Colloids Surfaces A Physicochem. Eng. Asp. 417 (2013) 32-38.

[59] Y. Zhang, J. Yu, H. Niu, H. Liu, J. Colloid Interface Sci. 313 (2007) 503-510.

[60] R. Herbois, S. Noël, B. Léger, L. Bai, A. Roucoux, E. Monflier, A. Ponchel, Chem. Commun. 48 (2012) 3451-3453. 
[61] F. Lu, J. Liu, J. Xu, Mater. Chem. Phys. 108 (2008) 369-374.

[62] M. Bonini, S. Rossi, G. Karlsson, M. Almgren, P. Lo Nostro, P. Baglioni, Langmuir 22 (2006) 1478-84.

[63] J.P. Lange, E. van der Heide, J. van Buijtenen, R. Price, ChemSusChem 5 (2012) 15066.

[64] J.W. Medlin, ACS Catal. 1 (2011) 1284-1297.

[65] M. Besson, P. Gallezot, C. Pinel, Chem. Rev. (2013). DOI: 10.1021/cr4002269

[66] S. Noël, B. Léger, R. Herbois, A. Ponchel, S. Tilloy, G. Wenz, E. Monflier, Dalton Trans. 41 (2012) 13359-13363.

[67] B. Escuder, F. Rodríguez-Llansola, J.F. Miravet, New J. Chem. 34 (2010) 1044.

[68] B. Léger, S. Menuel, A. Ponchel, F. Hapiot, E. Monflier, Adv. Synth. Catal. 354 (2012) $1269-1272$

[69] J. Dupont, J.D. Scholten, Chem. Soc. Rev. 39 (2010) 1780-804.

[70] N. Kania, S. Rio, E. Monflier, A. Ponchel, J. Colloid Interface Sci. 371 (2012) 89-100.

[71] A. Denicourt-Nowicki, A. Roucoux, F. Wyrwalski, N. Kania, E. Monflier, A. Ponchel, Chem. Eur. J. 14 (2008) 8090-3.

[72] F. Wyrwalski, B. Léger, C. Lancelot, A. Roucoux, E. Monflier, A. Ponchel, Appl. Catal. A Gen. 391 (2011) 334-341.

[73] A. Jean-Marie, A. Griboval-Constant, A.Y. Khodakov, E. Monflier, F. Diehl, Chem. Commun. 47 (2011) 10767-9.

[74] L. Bai, F. Wyrwalski, J.-F. Lamonier, A.Y. Khodakov, E. Monflier, A. Ponchel, Appl. Catal. B Environ. 138 (2013) 381-390. 


\section{Scheme captions}

Scheme 1. Cyclodextrins structure.

Scheme 2. RaMe-CD-stabilized $\mathrm{Ru}(0)$ NPs synthesis.

Scheme 3. Two methodologies for RaMe- $\beta-C D$-stabilized Ru(0) NPs synthesis.

Scheme 4. Acetophenone hydrogenation with RaMe- $\beta$-CD-stabilized Ru(0) NPs.

Scheme 5. Tert-butylacetophenone hydrogenation with RaMe- $\beta-C D$-stabilized Ru(0) NPs.

Scheme 6. Structure of RaMe- $\beta-C D$ grafted with chiral amino acid moieties.

Scheme 7. Dynamic organization of the stabilizers around the $\mathrm{Ru}(0) \mathrm{NPs}$.

Scheme 8. Synthesis of dppbs-stabilized Ru(0) NPs.

Scheme 9. Proposed mechanism for the PVP: CD-stabilized Ru(0) NPs synthesis.

Scheme 10. PolyCOO- $-\beta-\beta-C D$ structure.

Scheme 11. Thermoresponsive N-alkylpyridinium amphiphile- $(\alpha-\mathrm{CD})_{2}$ hydrogel obtained by self-assembly.

Scheme 12. Thermoregulated Ru NPs catalyzed hydrogenation of alkenes. 

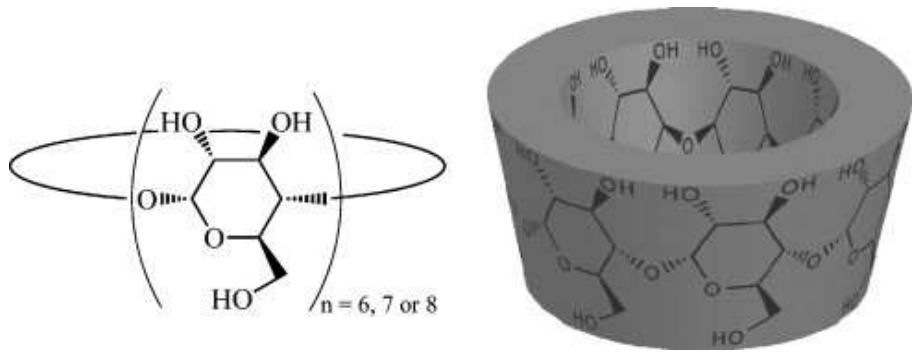

$\mathrm{n}=6 \alpha$-cyclodextrin $\mathrm{n}=7 \beta$-cyclodextrin $\mathrm{n}=8 \gamma$-cyclodextrin

Scheme 1. Cyclodextrins structure. 


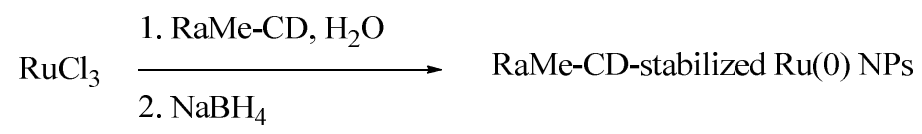

Scheme 2. RaMe-CD-stabilized Ru(0) NPs synthesis [25,26]. 


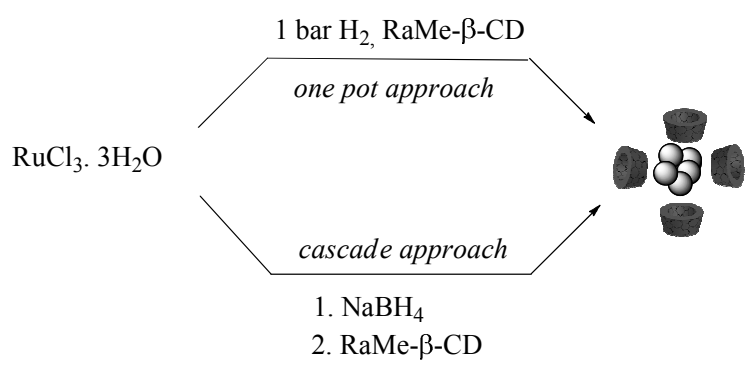

Scheme 3. Two methodologies for RaMe- $\beta$-CD-stabilized Ru(0) NPs synthesis [37]. 


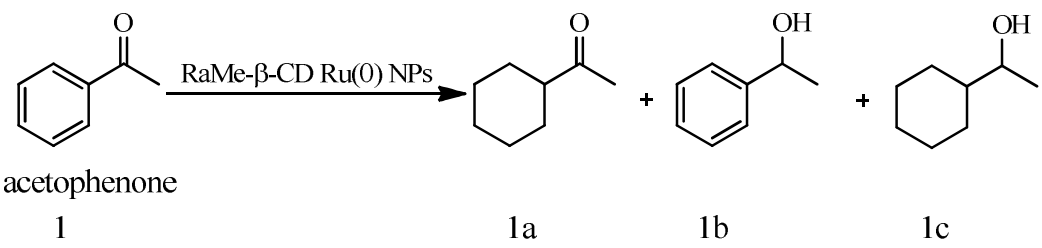

Scheme 4. Acetophenone hydrogenation with RaMe- $\beta$-CD-stabilized Ru(0) NPs [37]. 


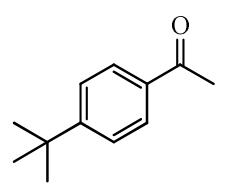

${ }^{\mathrm{t}} \mathrm{Bu}$-acetophenone 2

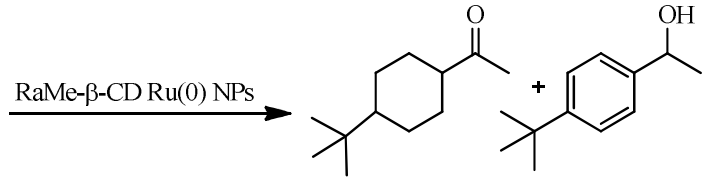

$2 \mathrm{a}$

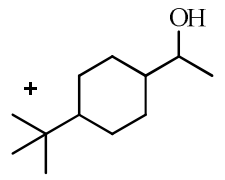

2c

Scheme 5. Tert-butylacetophenone hydrogenation with RaMe- $\beta-C D-s t a b i l i z e d ~ R u(0)$ NPs [37]. 


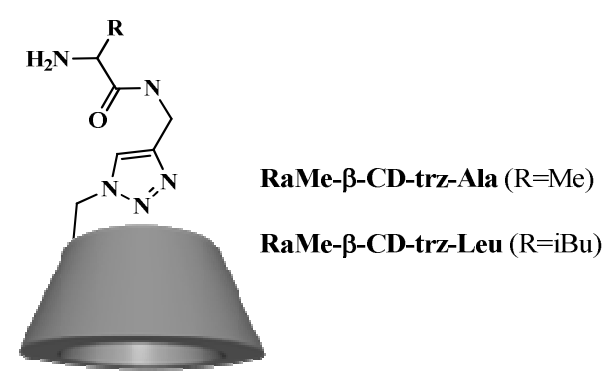

Scheme 6. Structure of RaMe- $\beta-C D$ grafted with chiral amino acid moieties [44]. 


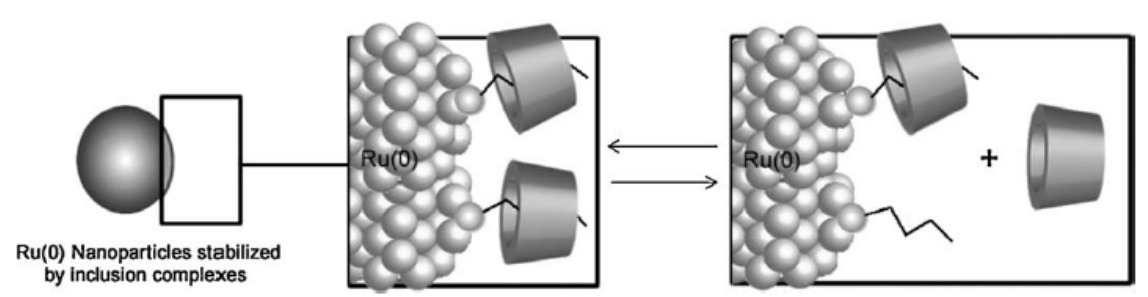

Scheme 7. Dynamic organization of the stabilizers around the $\mathrm{Ru}(0)$ NPs. Reprinted with permission from [46]. Copyright (2009) Royal Society of Chemistry. 


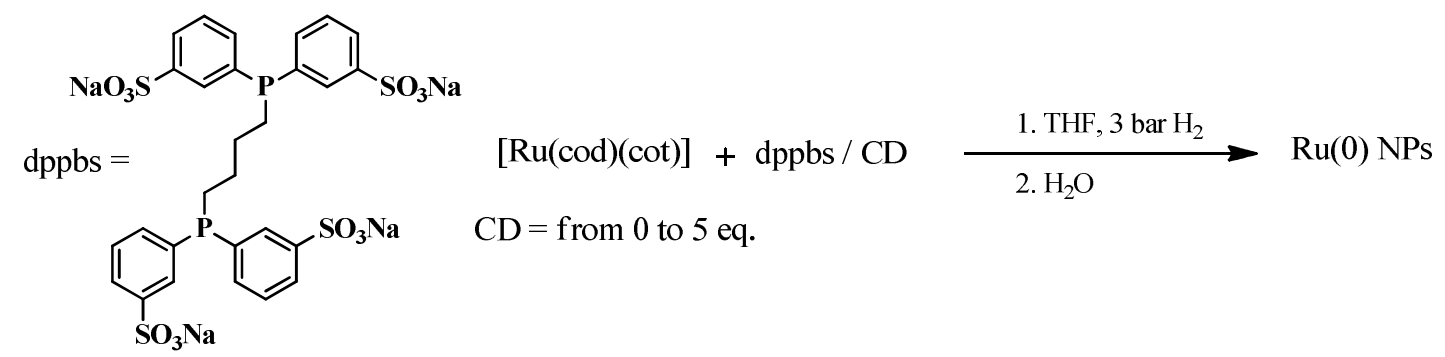

Scheme 8. Synthesis of dppbs-stabilized Ru(0) NPs [53]. 

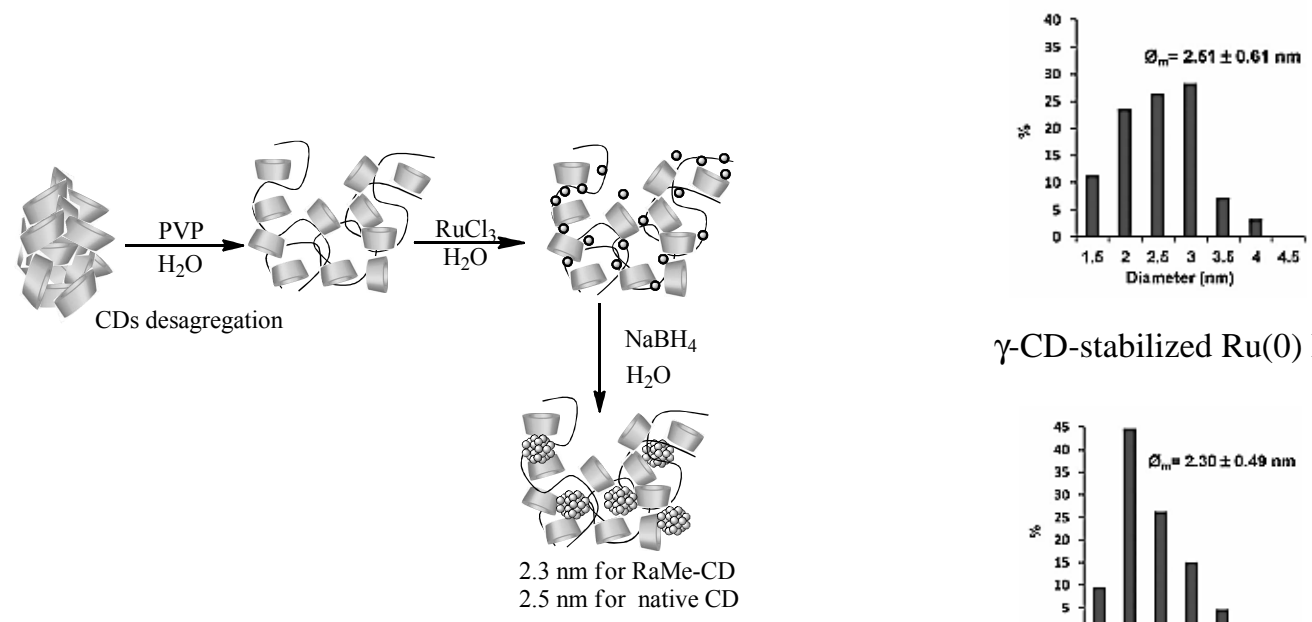

$\gamma$-CD-stabilized $\mathrm{Ru}(0) \mathrm{NPs}$

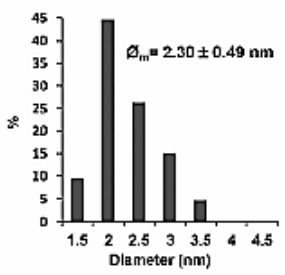

RaMe $\gamma$-CD-stabilized Ru(0) NPs

Scheme 9. Proposed mechanism for the PVP:CD-stabilized Ru(0) NPs synthesis. Reprinted with permission from [60]. Copyright (2012) Royal Society of Chemistry. 


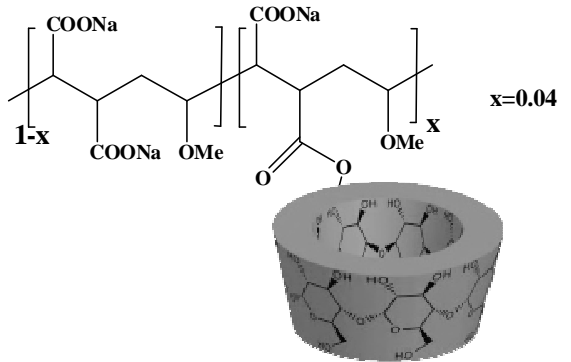

Scheme 10.PolyCOO- $g-\beta-C D$ structure [66]. 


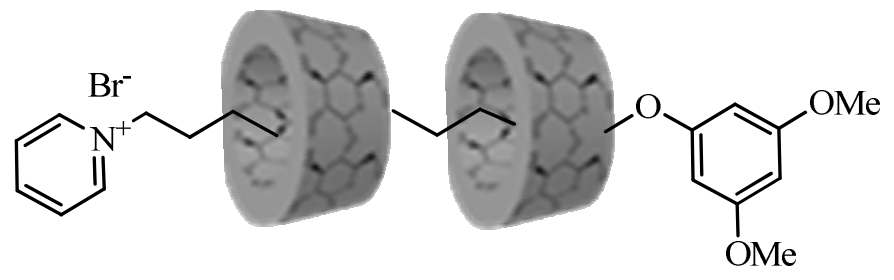

Scheme 11. Thermoresponsive N-alkylpyridinium amphiphile- $(\alpha-C D)_{2}$ hydrogel obtained by selfassembly [68]. 

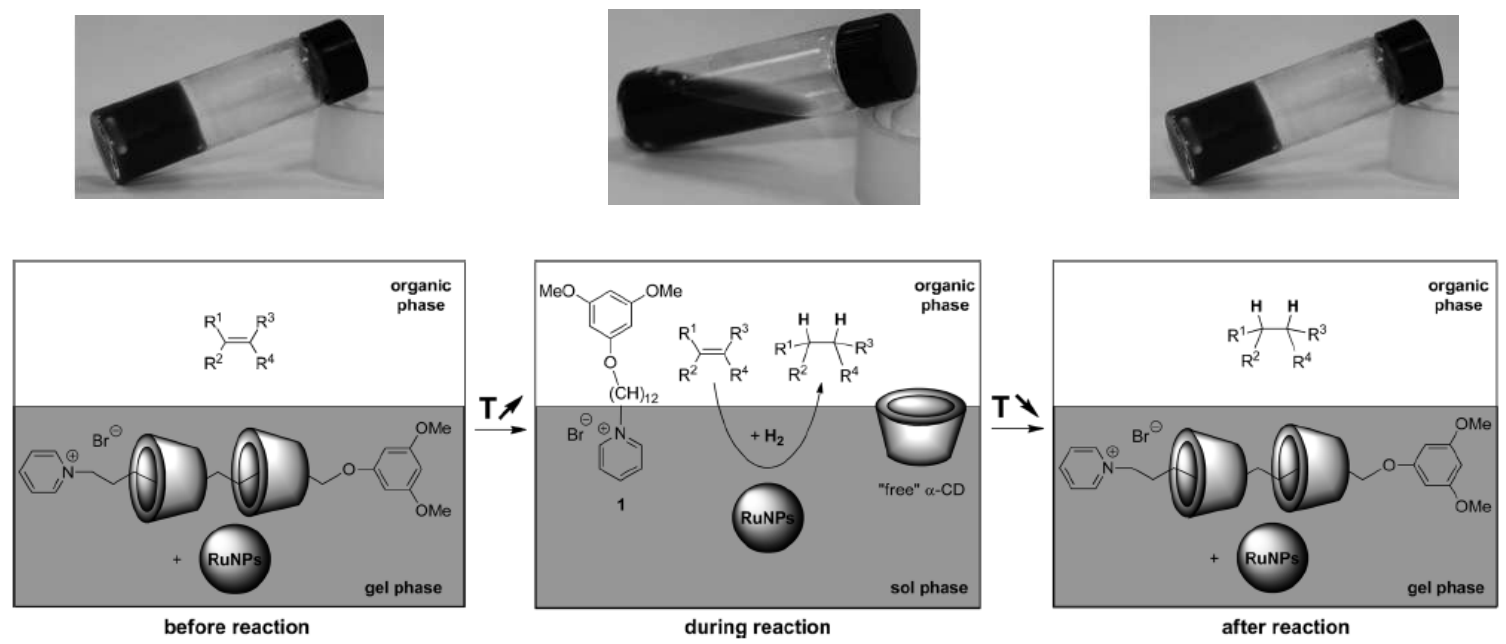

Scheme 12. Thermoregulated $\mathrm{Ru}(0)$ NPs catalyzed hydrogenation of alkenes. Reprinted with permission from [68]. Copyright (2012) Wiley-VCH Verlag GmbH \&Co. 


\section{Figure captions}

Fig.1. Transmission electron micrograph and size distribution of RaMe- $\beta-C D$-stabilized $R u(0)$ NPs.

Fig.2. Size distribution and TEM pictures of RaMe- $\beta$-CD-stabilized $\mathrm{Ru}(0)$ NPs prepared by the (a) one pot and (b) cascade approach.

Fig.3. Kinetics of acetophenone hydrogenation with RaMe- $\beta$-CD-stabilized Ru(0) NPs.

Fig.4. Job's plot derived from ${ }^{1} \mathrm{H}$ experimental data of $\beta$-CD.

Fig.5. Partial contour plot of the T-ROESY NMR (300 MHz) of a solution containing RaMe- $\beta$ ( $1 \mathrm{mM})$ and $\mathrm{HEA} 16 \mathrm{Cl}(1 \mathrm{mM})$ in $\mathrm{D}_{2} \mathrm{O}$ at $298 \mathrm{~K}$.

Fig.6. TEM and size distribution of Rh(0) NPs with PolyCOONa- $g-\beta-\mathrm{CD}$ (a) and PolyCOONa (b) as stabilizers.

Fig.7. Transmission electron micrograph (a) and size distribution of $\mathrm{Ru}(0) \mathrm{NPs}$.

Fig.8. TEM and size distribution of $\mathrm{Ru}-3 \beta-\mathrm{CD} / \mathrm{C}$ (3 molar eq. of $\mathrm{CD}$ to $\mathrm{Ru}$ ).

Fig.9. Cumulate TOF of $o$-xylene and $p$-xylene in mixture over $\mathrm{Ru}(0) / \mathrm{C}\left(85^{\circ} \mathrm{C}\right.$, feed composition $=420$ ppm $o$-xylene and $5810 \mathrm{ppm} p$-xylene in $\mathrm{H}_{2}$, total flow rate $\left.=60 \mathrm{~mL} \cdot \mathrm{min}^{-1}\right)$. 

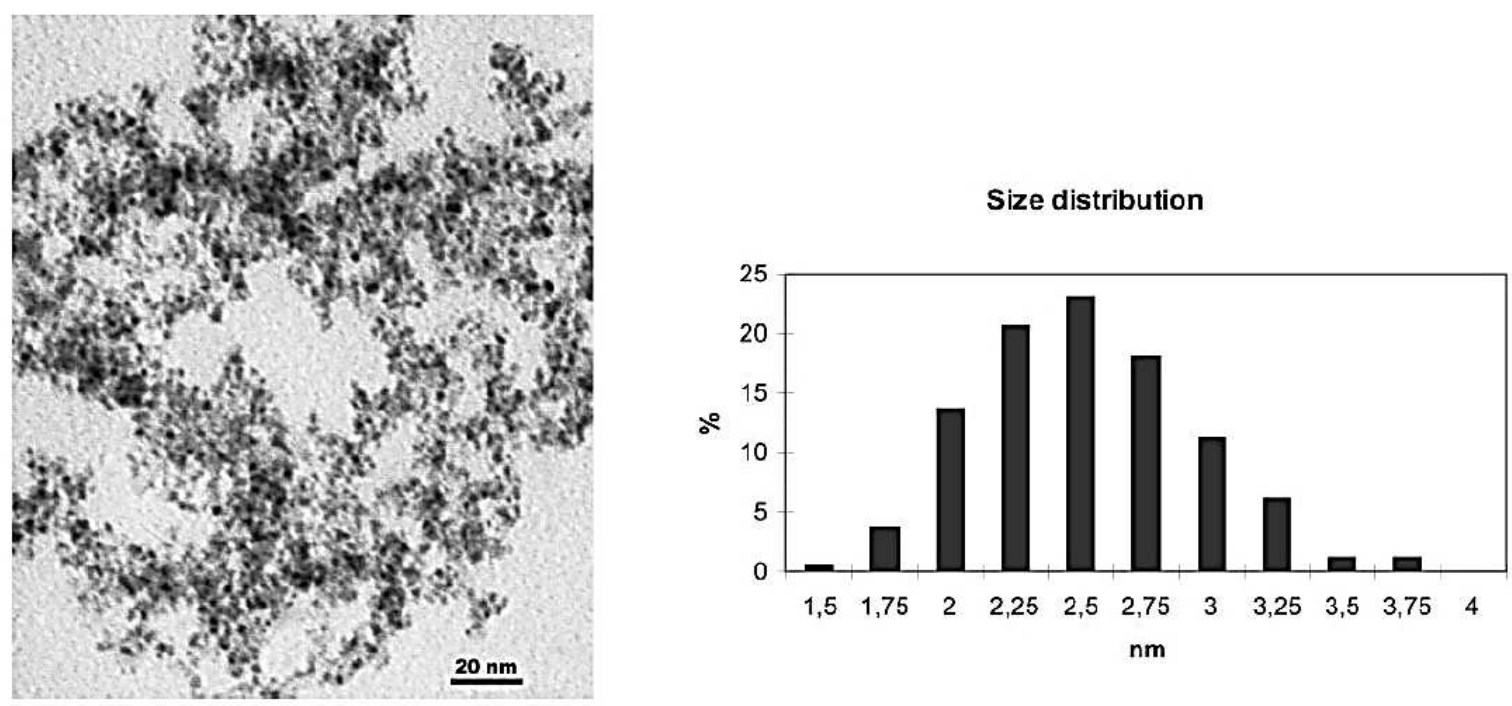

Fig.1. Transmission electron micrograph and size distribution of RaMe- $\beta-C D$-stabilized Ru(0) NPs. Reprinted with permission from [21]. Copyright (2007) Royal Society of Chemistry. 

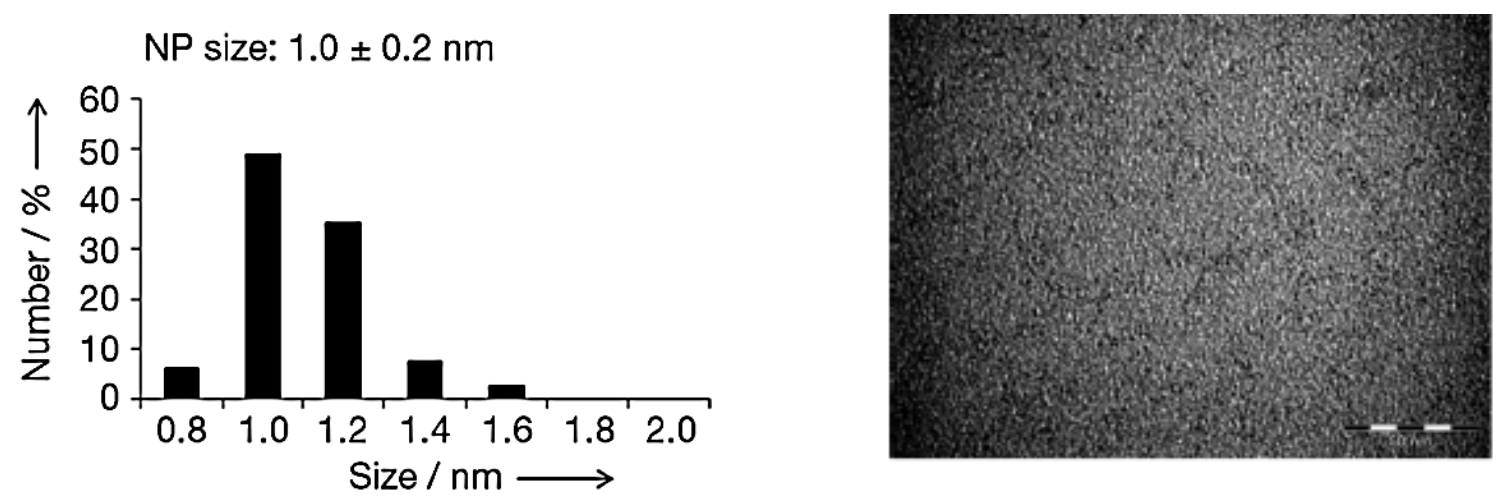

b
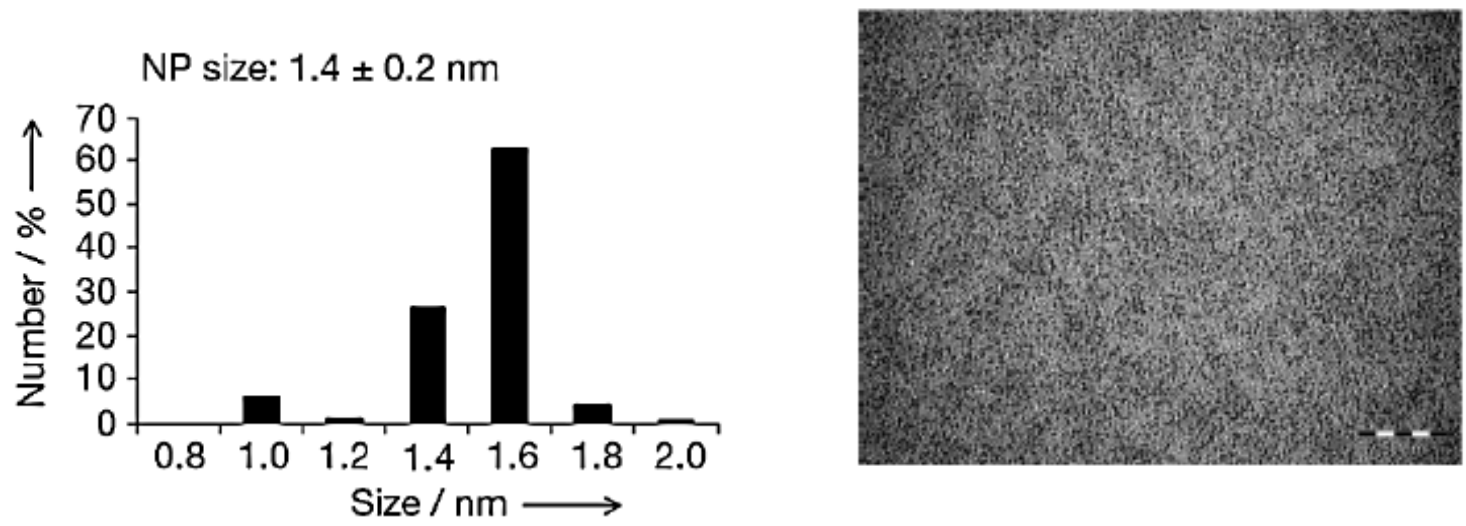

Fig.2. Size distribution and TEM pictures of RaMe- $\beta$-CD-stabilized $\mathrm{Ru}(0)$ NPs prepared by the (a) one pot and (b) cascade approach. Scale bars: $50 \mathrm{~nm}$. Reprinted with permission from [37]. Copyright (2013) Wiley-VCH Verlag GmbH \&Co. 


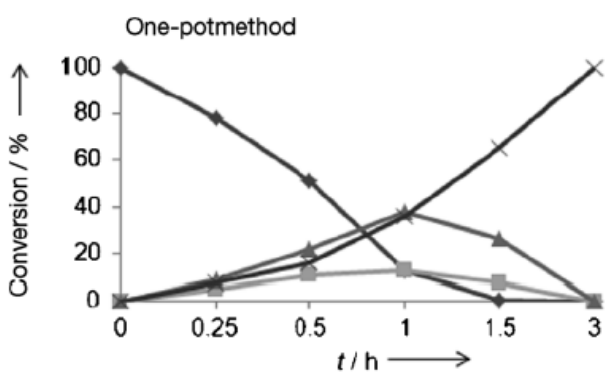

$\rightarrow 1 \rightarrow-1 a \multimap-1 b \div 1 c$

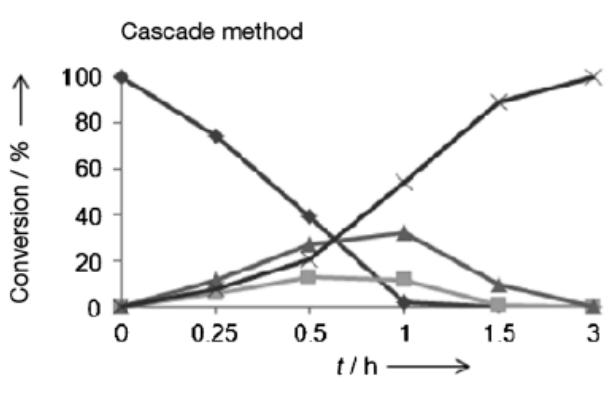<smiles>CC(=O)C1CCCCC1</smiles>

1a<smiles>CC(=O)c1ccccc1</smiles>

1<smiles>CC(O)c1ccccc1</smiles>

$1 \mathrm{~b}$<smiles>CC(O)C1CCCCC1</smiles>

$1 c$

Fig.3. Kinetics of acetophenone hydrogenation with RaMe- $\beta$-CD-stabilized Ru(0) NPs. Reprinted with permission from [37]. Copyright (2013) Wiley-VCH Verlag GmbH \&Co. 


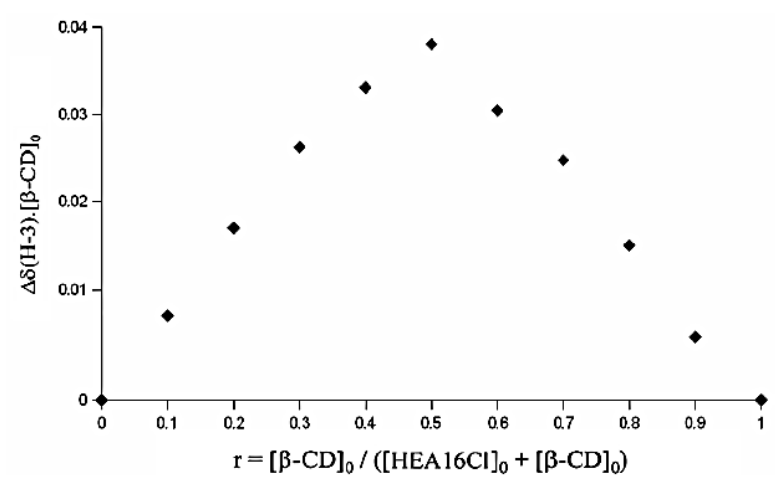

Fig.4. Job's plot derived from ${ }^{1} \mathrm{H}$ experimental data of $\beta$-CD. Reprinted with permission from [46]. Copyright (2009) Royal Society of Chemistry. 


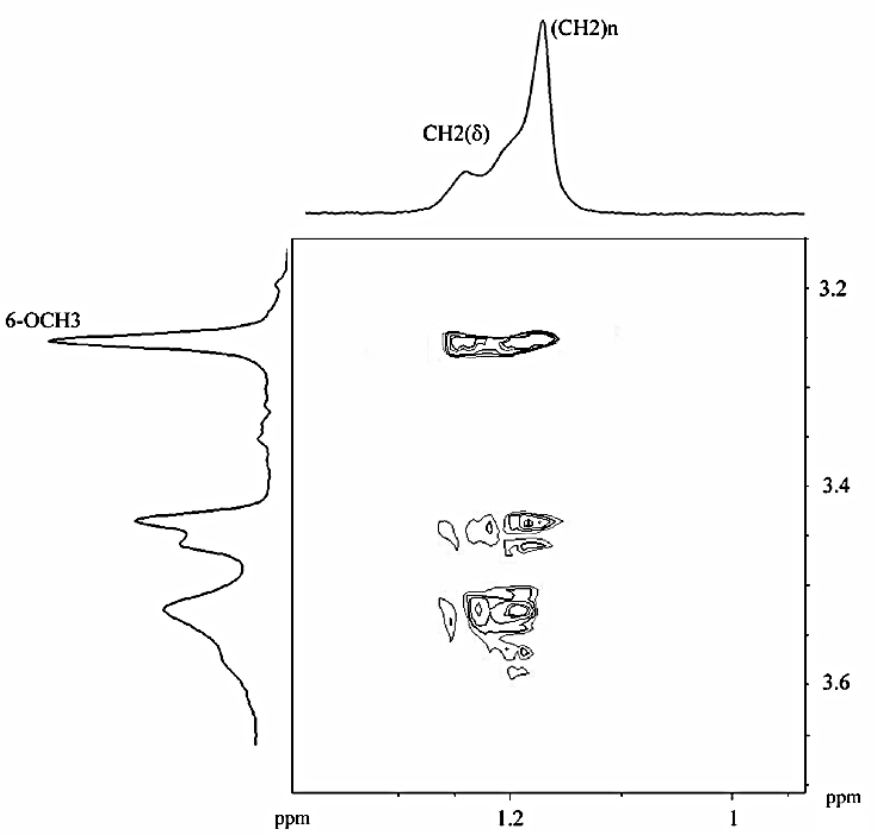

Fig.5. Partial contour plot of the T-ROESY NMR (300 MHz) of a solution containing RaMe- $\beta$ (1 $\mathrm{mM})$ and $\mathrm{HEA} 16 \mathrm{Cl}(1 \mathrm{mM})$ in $\mathrm{D}_{2} \mathrm{O}$ at $298 \mathrm{~K}$. Reprinted with permission from [46]. Copyright (2009) Royal Society of Chemistry. 


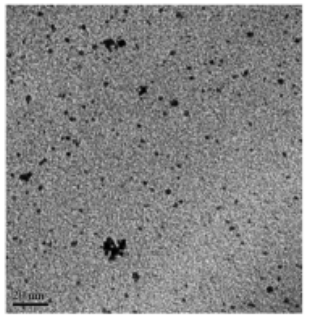

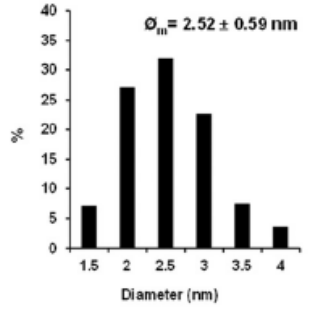

a

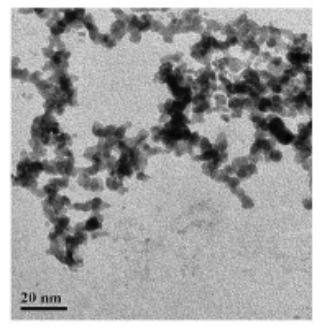

b

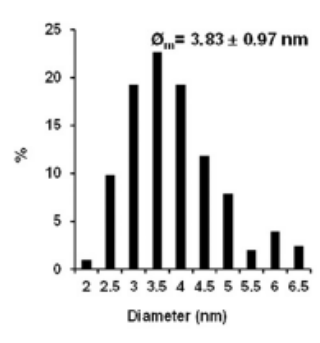

Fig.6. TEM and size distribution of Rh(0) NPs with PolyCOONa-g- $\beta-\mathrm{CD}$ (a) and PolyCOONa (b) as stabilizers. Reprinted with permission from [66]. Copyright (2012) Royal Society of Chemistry. 

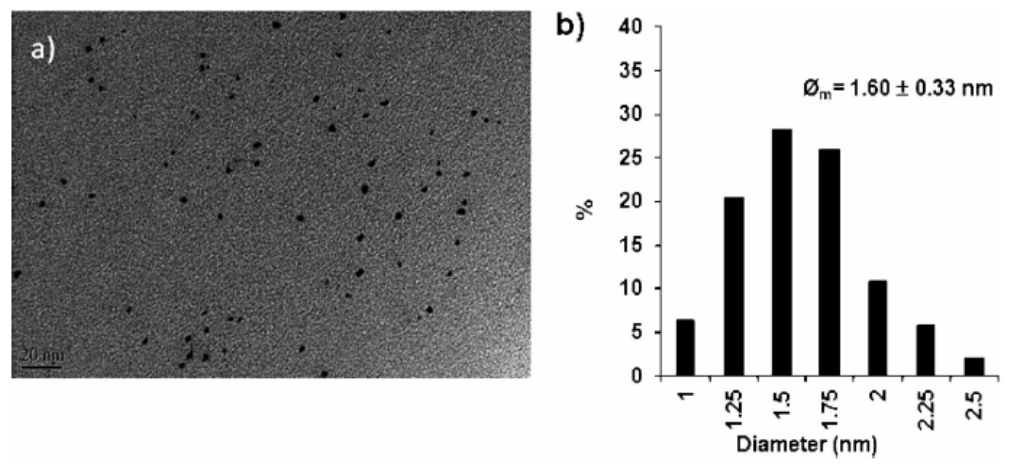

Fig.7. Transmission electron micrograph (a) and size distribution of $\mathrm{Ru}(0)$ NPs. Reprinted with permission from [68]. Copyright (2013) Wiley-VCH Verlag GmbH \&Co. 

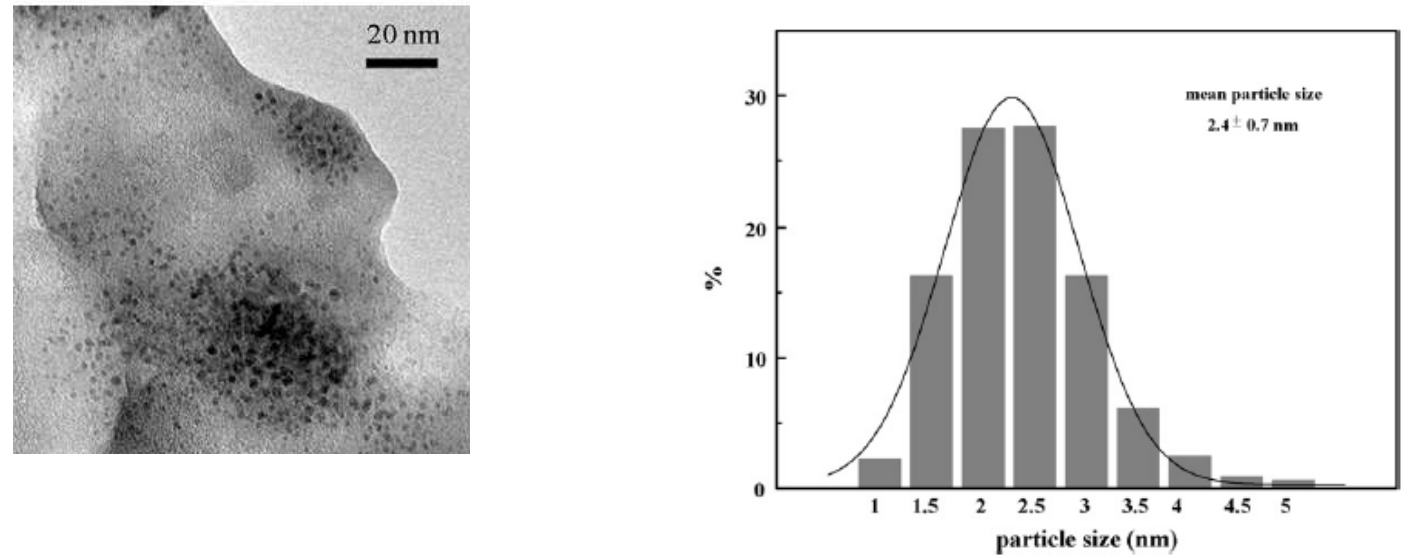

Fig.8. TEM and size distribution of $\mathrm{Ru}-3 \beta-\mathrm{CD} / \mathrm{C}$ ( 3 molar eq. of $\mathrm{CD}$ to $\mathrm{Ru}$ ). Reprinted with permission from [72]. Copyright (2011) Elsevier. 


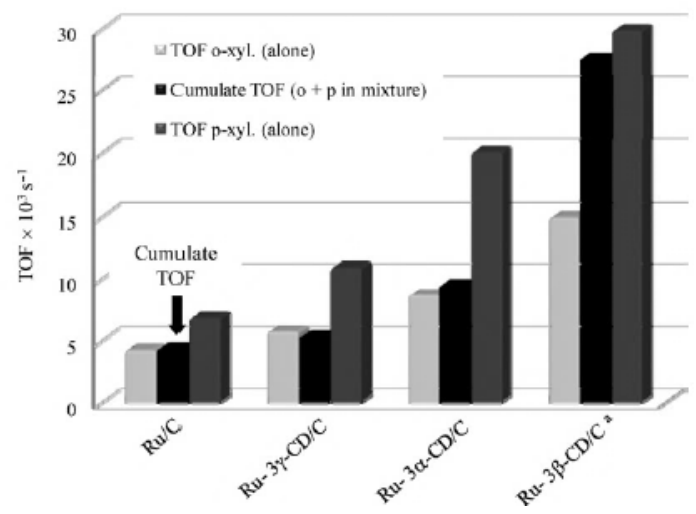

Fig.9. Cumulate TOF of $o$-xylene and $p$-xylene in mixture over $\mathrm{Ru}(0) / \mathrm{C}\left(85^{\circ} \mathrm{C}\right.$, feed composition $=$ $420 \mathrm{ppm} o$-xylene and $5810 \mathrm{ppm} p$-xylene in $\mathrm{H}_{2}$, total flow rate $\left.=60 \mathrm{~mL} \cdot \mathrm{min}^{-1}\right)$. ${ }^{a}$ Second preparation of Ru-3ß-CD/C. Reprinted with permission from [72]. Copyright (2011) Elsevier. 


\section{Table captions}

Table 1 Description of randomly methylated CDs.

Table 2 Hydrogenation of long chain alkenes in presence of RaMe-CD-stabilized Ru(0) NPs.

Table 3 Hydrogenation of monosubstituted aromatic compounds in presence of RaMe-CD-stabilized $\mathrm{Ru}(0) \mathrm{NPs}$.

Table 4 Hydrogenation of $\alpha$ - and $\beta$-pinenes with $\operatorname{Ru}(0)$ NPs.

Table 5 Hydrogenation of aromatic compounds with RaMe- $\beta$-CD/HEA16Cl-stabilized Ru(0) NPs.

Table 6 Arene derivatives hydrogenation catalyzed by $\mathrm{Ru}(0)$ NPs.

Table 7 Hydrogenation of furfural with $\mathrm{Ru}(0) \mathrm{NPs}$.

Table 8 TOFs and selectivities in xylene hydrogenation measured on ruthenium-based catalysts. 


\section{Table 1}

Description of randomly methylated CDs.

\begin{tabular}{c}
\hline \\
\hline Abbreviations \\
RaMe- $\alpha-C D$ \\
RaMe- $\beta-C D(1.8)$ \\
RaMe- $\beta-C D(0.7)$ \\
RaMe- $\gamma-C D$
\end{tabular}




\section{Table 2}

Hydrogenation of long chain alkenes in presence of RaMe-CD-stabilized Ru(0) NPs [26].

\begin{tabular}{|c|c|c|c|}
\hline Entry & Substrate & Cyclodextrin (DS) & TOF $\left(h^{-1}\right)^{b}$ \\
\hline 1 & Decene & $\mathrm{RaMe}-\alpha-\mathrm{CD}$ & 17 \\
\hline 2 & Decene & RaMe- $\beta-C D(0.7)$ & 18 \\
\hline 3 & Decene & RaMe- $\beta-C D(1.8)$ & 17 \\
\hline 4 & Decene & $\mathrm{RaMe}-\gamma-\mathrm{CD}$ & 22 \\
\hline 5 & Dodecene & RaMe- $\beta-C D(1.8)$ & 15 \\
\hline 6 & Tetradecene & RaMe- $\beta-C D(1.8)$ & 12 \\
\hline
\end{tabular}

${ }^{\mathrm{a} C}$ Conditions: catalyst $\left(1.4 \times 10^{-5} \mathrm{~mol}\right), \mathrm{CD}\left(1.4 \times 10^{-4} \mathrm{~mol}\right), 1$-dodecene $\left(1.4 \times 10^{-3} \mathrm{~mol}\right)$, hydrogen pressure $(1$ bar $)$, temperature $\left(20^{\circ} \mathrm{C}\right)$, stirring rate $(1500 \mathrm{rpm}), 10 \mathrm{~mL}$ water. ${ }^{\mathrm{b}}$ Turnover frequency defined as number of mol of substrate per mol of ruthenium per hour. 


\section{Table 3}

Hydrogenation of monosubstituted aromatic compounds in presence of RaMe-CD-stabilized $\mathrm{Ru}(0)$ NPs [26]. ${ }^{\mathrm{a}}$

\begin{tabular}{ccccc}
\hline Entry & Substrate & RaMe-CD(DS) & Product & TOF $\left(\mathrm{h}^{-1}\right)^{\mathrm{b}}$ \\
\hline 1 & Benzene & RaMe- $\alpha-\mathrm{CD}$ & Benzene & - \\
2 & Benzene & RaMe- $\beta-\mathrm{CD}(0.7)$ & Cyclohexane & 25 \\
3 & Benzene & RaMe- $\beta-\mathrm{CD}(1.8)$ & Cyclohexane & 25 \\
4 & Benzene & RaMe- $\gamma-\mathrm{CD}$ & Cyclohexane & 10 \\
5 & Styrene & RaMe- $\alpha-\mathrm{CD}$ & Ethylbenzene & 10 \\
6 & Styrene & RaMe- $\beta-\mathrm{CD}(0.7)$ & Ethylcyclohexane & 9 \\
7 & Styrene & RaMe- $\beta-\mathrm{CD}(1.8)$ & Ethylbenzene & 9 \\
8 & Styrene & RaMe- $\gamma-\mathrm{CD}$ & Ethylcyclohexane & 4 \\
9 & Ethylbenzene & RaMe- $\alpha-\mathrm{CD}$ & Ethylbenzene & - \\
10 & Ethylbenzene & RaMe- $\beta-\mathrm{CD}(0.7)$ & Ethylcyclohexane & 9 \\
11 & Ethylbenzene & RaMe- $\beta-\mathrm{CD}(1.8)$ & Ethylbenzene & - \\
12 & Ethylbenzene & RaMe- $\gamma-\mathrm{CD}$ & Ethylcyclohexane & 4 \\
13 & Toluene & RaMe- $\beta-\mathrm{CD}(0.7)$ & Methylcyclohexane & 17 \\
14 & Toluene & RaMe- $\beta-\mathrm{CD}(1.8)$ & Methylcyclohexane & 17 \\
15 & Allylbenzene & RaMe- $\beta-\mathrm{CD}(0.7)$ & Propylcyclohexane & 8 \\
16 & Allylbenzene & RaMe- $\beta-\mathrm{CD}(1.8)$ & Propylbenzene & 34 \\
17 & Propylbenzene & RaMe- $\beta-\mathrm{CD}(0.7)$ & Propylcyclohexane & 9 \\
18 & Propylbenzene & RaMe- $\beta-\mathrm{CD}(1.8)$ & Propylbenzene & - \\
\hline
\end{tabular}

${ }^{\mathrm{a}}$ Conditions: $\mathrm{Ru}\left(1.5 \times 10^{-5} \mathrm{~mol}\right), \mathrm{CD}\left(1.5 \times 10^{-4} \mathrm{~mol}\right)$, substrate $\left(1.5 \times 10^{-3} \mathrm{~mol}\right)$, hydrogen pressure $(1 \mathrm{bar})$, temperature $\left(20^{\circ} \mathrm{C}\right)$, stirring rate $(1500 \mathrm{rpm}), 10 \mathrm{~mL}$ water, $24 \mathrm{~h}$. ${ }^{\mathrm{b}}$ Turnover frequency defined as number of mol of substrate per mol of ruthenium per hour. 


\section{Table 4}

Hydrogenation of $\alpha$ - and $\beta$-pinenes with $\operatorname{Ru}(0)$ NPs [26].

\begin{tabular}{|c|c|c|c|c|}
\hline Entry & Substrate & Stabilizing agent & time $^{b}$ & d.e. $(\%)^{\mathrm{c}}$ \\
\hline 1 & $\alpha$-pinene & RaMe- $\alpha-C D$ & 24 & 96 \\
\hline 2 & $\alpha$-pinene & RaMe- $\beta-C D(0.7)$ & 41 & 94 \\
\hline 3 & $\alpha$-pinene & RaMe- $\beta-C D(1.8)$ & 40 & 93 \\
\hline 4 & $\alpha$-pinene & RaMe- $\gamma-\mathrm{CD}$ & 9 & 95 \\
\hline 5 & $\alpha$-pinene & HEA16Cl & 30 & 88 \\
\hline 6 & $\beta$-pinene & RaMe- $\alpha-C D$ & 6 & 74 \\
\hline 7 & $\beta$-pinene & RaMe- $\beta-C D(0.7)$ & 4 & 57 \\
\hline 8 & $\beta$-pinene & RaMe- $\beta-\mathrm{CD}(1.8)$ & 4 & 52 \\
\hline 9 & $\beta$-pinene & $\mathrm{RaMe}-\gamma-\mathrm{CD}$ & 24 & 75 \\
\hline 10 & $\beta$-pinene & HEA16Cl & 15 & 50 \\
\hline
\end{tabular}

${ }^{\mathrm{a} C}$ Conditions: $\mathrm{Ru}\left(1.5 \times 10^{-5} \mathrm{~mol}\right), \mathrm{CD}\left(1.5 \times 10^{-4} \mathrm{~mol}\right)$, substrate $\left(1.5 \times 10^{-3} \mathrm{~mol}\right)$, hydrogen pressure $(1 \mathrm{bar})$, temperature $\left(20^{\circ} \mathrm{C}\right)$, stirring rate $(1500 \mathrm{rpm}), 10 \mathrm{~mL}$ water. ${ }^{\mathrm{b}}$ time corresponding to total conversion. ${ }^{\mathrm{c}}$ diastereoisomeric excess. 


\section{Table 5}

Hydrogenation of aromatic compounds with RaMe- $\beta$-CD/HEA16Cl-stabilized Ru(0) NPs [46]. ${ }^{\mathrm{a}}$

\begin{tabular}{cccc}
\hline Entry & Substrate & Stabilizer & TOF $\left(\mathbf{h}^{-\mathbf{1}}\right)^{\mathbf{b}}$ \\
\hline 1 & Anisole & HEA16Cl & 3.4 \\
2 & Anisole & RaMe- $\beta-C D / H E A 16 C l$ & 10.2 \\
3 & Toluene & HEA16Cl & 2.2 \\
4 & Toluene & RaMe- $\beta-C D / H E A 16 C l$ & 10.1 \\
5 & Styrene & HEA16Cl & 14.3 \\
6 & Styrene & RaMe- $\beta-C D / H E A 16 C l$ & 26.7 \\
\hline
\end{tabular}

${ }^{\mathrm{a}}$ Conditions: Ru $\left(3.8 \times 10^{-5} \mathrm{~mol}\right)$, HEA16Cl $\left(7.6 \times 10^{-5} \mathrm{~mol}\right)$ or HEA16Cl $\left(3.8 \times 10^{-5} \mathrm{~mol}\right)+\mathrm{RaMe}-\beta-\mathrm{CD}\left(3.8 \times 10^{-5} \mathrm{~mol}\right)$, substrate $\left(3.8 \times 10^{-3} \mathrm{~mol}\right)$, hydrogen pressure $(1 \mathrm{bar})$, temperature $\left(20^{\circ} \mathrm{C}\right)$, stirring rate $(1500 \mathrm{rpm}), 10 \mathrm{~mL}$ water. ${ }^{\mathrm{b}}$ Based on hydrogen consumption 


\section{Table 6}

Arene derivatives hydrogenation catalyzed by $\mathrm{Ru}(0) \mathrm{NPs}$ [53].

\begin{tabular}{|c|c|c|c|}
\hline Entry & Substrate & Stabilizer & TOF $\left(h^{-1}\right)^{b}$ \\
\hline 1 & Styrene & dppbs & 67 \\
\hline 2 & Styrene & $\mathrm{dppbs} / 0.2 \mathrm{RaMeCD}$ & 162 \\
\hline 3 & Styrene & dppbs/1.0 RaMeCD & 604 \\
\hline 4 & Styrene & dppbs/5.0 RaMeCD & 2448 \\
\hline 5 & Acetophenone & dppbs & 36 \\
\hline 6 & Acetophenone & dppbs/0.2 C RaMeCD & 89 \\
\hline 7 & Acetophenone & dppbs/1.0 RaMeCD & 257 \\
\hline 8 & Acetophenone & $\mathrm{dppbs} / 5.0 \mathrm{RaMeCD}$ & 944 \\
\hline 9 & $m$-Methylanisole & dppbs & 28 \\
\hline 10 & $m$-Methylanisole & dppbs/0.2 RaMeCD & 89 \\
\hline 11 & $m$-Methylanisole & dppbs/1.0 RaMeCD & 295 \\
\hline 12 & $m$-Methylanisole & dppbs/5.0 RaMeCD & 1350 \\
\hline
\end{tabular}

${ }^{\mathrm{a} C}$ Conditions: $\mathrm{Ru}$ NPs $(10 \mathrm{mg})$, substrate $\left(3.9 \times 10^{-3} \mathrm{~mol}\right)$, hydrogen pressure $(10 \mathrm{bar})$, temperature $\left(20^{\circ} \mathrm{C}\right)$, time $(120$ $\mathrm{min}), 10 \mathrm{~mL}$ water. ${ }^{\mathrm{b}}$ Turnover frequency defined as number of mol of substrate per mol of ruthenium per hour. 


\section{Table 7}

Hydrogenation of furfural with $\mathrm{Ru}(0) \mathrm{NPs}[60] .{ }^{\mathrm{a}}$

\begin{tabular}{|c|c|c|c|c|}
\hline Entry & CD & PVP/CD & Conversion (\%) & FA selectivity (\%) \\
\hline & - & $8: 0$ & 30 & 94 \\
\hline 1 & $\alpha-C D$ & $8: 2$ & 30 & 95 \\
\hline 2 & $\gamma-\mathrm{CD}$ & $8: 2$ & 38 & 94 \\
\hline 3 & RaMe- $\alpha-C D$ & $8: 2$ & 34 & 97 \\
\hline 4 & $\mathrm{RaMe}-\gamma$-CD & $8: 2$ & 61 & 90 \\
\hline 5 & RaMe- $\beta-C D$ & $8: 2$ & 53 & 90 \\
\hline 6 & RaMe- $\beta-C D$ & $8: 0.5$ & 37 & 97 \\
\hline 7 & RaMe- $\beta-C D$ & $8: 1$ & 52 & 93 \\
\hline 8 & RaMe- $\beta-C D$ & $8: 4$ & 52 & 90 \\
\hline
\end{tabular}

${ }^{\mathrm{a}}$ Conditions: $\mathrm{Ru}(0)\left(3.8 \times 10^{-5} \mathrm{~mol}\right), \mathrm{PVP}-\mathrm{K} 30\left(3.0 \times 10^{-4} \mathrm{~mol}\right)$, substrate/ $\mathrm{Ru}(0)(\mathrm{mol} / \mathrm{mol})=50, \mathrm{H}_{2} \mathrm{O}(12 \mathrm{~mL}), \mathrm{H}_{2}(10 \mathrm{bar})$, stirring rate $(750 \mathrm{rpm}), 30^{\circ} \mathrm{C}, 1.5 \mathrm{~h}$. 


\section{Table 8}

TOFs and selectivities in xylene hydrogenation measured on ruthenium-based catalysts [72]. ${ }^{\mathrm{a}}$

\begin{tabular}{|c|c|c|c|c|}
\hline Entry & Substrate & Catalyst & $\mathrm{TOF} \times 10^{3 \mathrm{~b}}$ & Trans sel (\%) \\
\hline 1 & $o$-xylene & $\mathrm{Ru} / \mathrm{C}$ & 4.2 & 0.9 \\
\hline 2 & $o$-xylene & $\mathrm{Ru}-3 \gamma-\mathrm{CD} / \mathrm{C}$ & 5.7 & 2.1 \\
\hline 3 & $o$-xylene & $\mathrm{Ru}-3 \alpha-\mathrm{CD} / \mathrm{C}$ & 8.6 & 1.8 \\
\hline 4 & $o$-xylene & $\mathrm{Ru}-3 \beta-\mathrm{CD} / \mathrm{C}$ & 14.9 & 3.9 \\
\hline 5 & $o$-xylene & $\mathrm{Ru}-1.5 \beta-\mathrm{CD} / \mathrm{C}$ & 8.6 & 3.4 \\
\hline 6 & $o$-xylene & $\mathrm{Ru}-5 \beta-\mathrm{CD} / \mathrm{C}$ & 7.4 & 2.6 \\
\hline 7 & $o$-xylene & $\mathrm{Ru}-10 \beta-\mathrm{CD} / \mathrm{C}$ & 9.9 & 2.8 \\
\hline 8 & $m$-xylene & $\mathrm{Ru} / \mathrm{C}$ & 6.6 & 7.5 \\
\hline 9 & $m$-xylene & $\mathrm{Ru}-3 \gamma-\mathrm{CD} / \mathrm{C}$ & 11.3 & 8.3 \\
\hline 10 & $m$-xylene & $\mathrm{Ru}-3 \alpha-\mathrm{CD} / \mathrm{C}$ & 20.5 & 8.8 \\
\hline 11 & $m$-xylene & $\mathrm{Ru}-3 \beta-\mathrm{CD} / \mathrm{C}$ & 30.5 & 11.4 \\
\hline 12 & $p$-xylene & $\mathrm{Ru} / \mathrm{C}$ & 6.7 & 15.0 \\
\hline 13 & $p$-xylene & $\mathrm{Ru}-3 \gamma-\mathrm{CD} / \mathrm{C}$ & 10.8 & 15.3 \\
\hline 14 & $p$-xylene & $\mathrm{Ru}-3 \alpha-\mathrm{CD} / \mathrm{C}$ & 20.0 & 16.7 \\
\hline 15 & $p$-xylene & $\mathrm{Ru}-3 \beta-\mathrm{CD} / \mathrm{C}$ & 29.8 & 21.9 \\
\hline
\end{tabular}

${ }^{a}$ Conditions: $85^{\circ} \mathrm{C}$, carrier gas $=\mathrm{H}_{2}, \mathrm{H}_{2}:$ xylene $=100: 1$, total flow rate $=60 \mathrm{~mL} \cdot \mathrm{min}^{-1} .{ }^{\mathrm{b}}$ Turnover frequency defined as number of mol of substrate per mol of ruthenium per hour. 